\title{
Experimental design for three interrelated marine ice sheet and ocean model intercomparison projects: MISMIP v. 3 (MISMIP+), ISOMIP v. 2 (ISOMIP+) and MISOMIP v. 1 (MISOMIP1)
}

\author{
Xylar S. Asay-Davis ${ }^{1}$, Stephen L. Cornford ${ }^{2}$, Gaël Durand ${ }^{3,4}$, Benjamin K. Galton-Fenzi ${ }^{5,6}$, Rupert M. Gladstone ${ }^{6,7}$, \\ G. Hilmar Gudmundsson ${ }^{8}$, Tore Hattermann ${ }^{9,10}$, David M. Holland ${ }^{11}$, Denise Holland ${ }^{12}$, Paul R. Holland ${ }^{8}$, \\ Daniel F. Martin ${ }^{13}$, Pierre Mathiot ${ }^{8,14}$, Frank Pattyn ${ }^{15}$, and Hélène Seroussi ${ }^{16}$ \\ ${ }^{1}$ Earth System Analysis, Potsdam Institute for Climate Impact Research, Potsdam, Germany \\ ${ }^{2}$ Centre for Polar Observation and Modelling, University of Bristol, Bristol, UK \\ ${ }^{3}$ CNRS, LGGE, 38041 Grenoble, France \\ ${ }^{4}$ Univ. Grenoble Alpes, LGGE, 38041 Grenoble, France \\ ${ }_{6}^{5}$ Australian Antarctic Division, Kingston, Tasmania, Australia \\ ${ }^{6}$ Antarctic Climate and Ecosystems Cooperative Research Centre, Hobart, Tasmania, Australia \\ ${ }^{7}$ Versuchsanstalt für Wasserbau, Hydrologie und Glaziologie (VAW), ETH Zurich, Switzerland \\ ${ }^{8}$ British Antarctic Survey, Cambridge, UK \\ ${ }^{9}$ Akvaplan-niva, Troms $\varnothing$, Norway \\ ${ }^{10}$ Alfred Wegener Institute, Helmholtz Centre for Polar and Marine Research, Bremerhaven, Germany \\ ${ }^{11}$ Courant Institute of Mathematical Sciences, New York University, New York, NY, USA \\ ${ }^{12}$ Center for Global Sea Level Change, New York University Abu Dhabi, Abu Dhabi, UAE \\ ${ }^{13}$ Lawrence Berkeley National Laboratory, Berkeley, CA, USA \\ ${ }^{14}$ Met Office, Exeter, UK \\ ${ }^{15}$ Laboratoire de Glaciologie, Université Libre de Bruxelles, Brussels, Belgium \\ ${ }^{16}$ Jet Propulsion Laboratory, California Institute of Technology, Pasadena, CA, USA
}

Correspondence to: Xylar S. Asay-Davis (xylar.asay-davis@pik-potsdam.de)

Received: 4 October 2015 - Published in Geosci. Model Dev. Discuss.: 11 November 2015

Revised: 28 April 2016 - Accepted: 2 July 2016 - Published: 25 July 2016

\begin{abstract}
Coupled ice sheet-ocean models capable of simulating moving grounding lines are just becoming available. Such models have a broad range of potential applications in studying the dynamics of marine ice sheets and tidewater glaciers, from process studies to future projections of ice mass loss and sea level rise. The Marine Ice Sheet-Ocean Model Intercomparison Project (MISOMIP) is a community effort aimed at designing and coordinating a series of model intercomparison projects (MIPs) for model evaluation in idealized setups, model verification based on observations, and future projections for key regions of the West Antarctic Ice Sheet (WAIS).

Here we describe computational experiments constituting three interrelated MIPs for marine ice sheet models and regional ocean circulation models incorporating ice shelf
\end{abstract}

cavities. These consist of ice sheet experiments under the Marine Ice Sheet MIP third phase (MISMIP+), ocean experiments under the Ice Shelf-Ocean MIP second phase (ISOMIP+) and coupled ice sheet-ocean experiments under the MISOMIP first phase (MISOMIP1). All three MIPs use a shared domain with idealized bedrock topography and forcing, allowing the coupled simulations (MISOMIP1) to be compared directly to the individual component simulations (MISMIP+ and ISOMIP+). The experiments, which have qualitative similarities to Pine Island Glacier Ice Shelf and the adjacent region of the Amundsen Sea, are designed to explore the effects of changes in ocean conditions, specifically the temperature at depth, on basal melting and ice dynamics. In future work, differences between model results will form the basis for the evaluation of the participating models. 


\section{Introduction}

The Marine Ice Sheet-Ocean Model Intercomparison Project (MISOMIP) is a targeted activity of the World Climate Research Programme's Climate and Cryosphere (CliC) project. MISOMIP is a community effort aimed at better quantifying sea-level change induced by increased mass loss from the West Antarctic Ice Sheet (WAIS), particularly the Amundsen Sea region. At the first MISOMIP workshop ${ }^{1}$, participants decided that intercomparisons of ice sheet-ocean dynamics in realistic configurations would be more credible if it was preceded by a more idealized intercomparison and evaluation process for the stand-alone components and coupled models involved. While MISOMIP's longer-term goal is to investigate WAIS, participants in the workshop felt that the idealized model intercomparison projects (MIPs) would be applicable to a wide variety of models used to investigate a number of processes related to ice sheet and glacier interactions with the ocean. In addition to model evaluation, these idealized MIPs should be designed as a framework for exploring and comparing emergent properties of the coupled system.

\subsection{Marine Ice Sheet Model Intercomparison Projects (MISMIPs)}

At the time of the workshop, two previous MIPs focused on verifying and evaluating stand-alone ice-sheet models for marine ice sheets had taken place and a third was under development. The first MISMIP (Pattyn et al., 2012) compared the grounding-line dynamics between 14 models with a total of 27 unique configurations, and with a semi-analytic solution (Schoof, 2007a, b). The MISMIP experiments were designed for flow-line models in which topography and other model fields varied in only one horizontal dimension (1HD). Within each experiment, a parameter (the ice softness) was varied through a series of discrete values, leading to advance and subsequent retreat of the grounding line. At each stage of the advance and retreat cycle, the model was allowed to reach steady state, typically over timescales of thousands to tens of thousands of years. The results showed that steady-state grounding-line positions could differ markedly depending on the resolution, type of stress approximation, and discretization methods employed. Comparison between the semi-analytic solution and high-resolution models with adaptive grids allowed the community to assess which model configurations gave accurate results and which configurations were likely not appropriate for marine ice-sheet studies. An important finding of MISMIP related studies (Durand et al., 2009; Gladstone et al., 2010; Cornford et al., 2013) was that models with fixed grids (as opposed to those that track the grounding line in time) and without sub-grid-scale pa-

\footnotetext{
${ }^{1}$ Rising Coastal Seas on a Warming Earth, New York University Abu Dhabi, Abu Dhabi, UAE, 27-29 October 2014, http://nyuad.nyu.edu/en/news-events/abu-dhabi-events/2014/10/ rising-coastal-seas-on-a-warming-earth.html
}

rameterizations of the grounding line require grounding-line resolution on the order of hundreds of meters to accurately reproduce grounding-line dynamics.

The second ice-sheet MIP, MISMIP3d (Pattyn et al., 2013), aimed at exploring grounding-line dynamics on centennial timescales in a configuration that varied in 2HDs. Dynamic changes were induced through a perturbation in the basal slipperiness in the center of the domain near the grounding line. MISMIP3d also tested the reversibility of the grounding-line position once the perturbation was removed. Results from 16 models with a total of 33 unique configurations showed that initial steady states as well as the reversibility of the dynamics differed significantly depending on the stress approximation and horizontal resolution.

Both MISMIP and MISMIP3d provided a basis for a number of follow-up studies focused on both improvements in numerical methods (e.g., Drouet et al., 2013; Leguy et al., 2014; Feldmann et al., 2014; Seroussi et al., 2014b) and exploring changes in the model topography and physics parameterizations (e.g., Leguy et al., 2014; Feldmann and Levermann, 2015; Tsai et al., 2015).

The third marine ice-sheet MIP (MISMIP+), described in Sect. 2, examines marine ice-sheet dynamics in 2HDs with strong buttressing. An idealized bedrock topography, based on the work of Gudmundsson et al. (2012) and Gudmundsson (2013), was designed to produce a steady state featuring a grounding line lying partly on a retrograde slope in the absence of ice shelf melt. The three major MISMIP+ experiments prescribe melt rates varying from no melt in a control experiment, to strong melt rates, concentrated either close to or far from the grounding line, which are expected to drive rapid grounding-line retreat (up to $\sim 50 \mathrm{~km}$ per century), followed by re-advance when the melt rates are restored to zero.

\subsection{Ice Shelf-Ocean Model Intercomparison Projects (ISOMIPs)}

ISOMIP was designed in an effort to identify systematic differences between ocean models with sub-shelf cavities. The specifications for the first ISOMIP (Holland et al., 2003; Hunter, 2006) included three idealized experiments with subice-shelf cavities based on Grosfeld et al. (1997). In the first experiment, the entire domain was covered by an ice shelf while the second and third experiments included a sharp calving front and a region of open ocean with simplified atmospheric/sea ice forcing in the form of surface restoring of temperature and salinity. The restoring was constant in time for the second experiment and varied seasonally in the third. Each experiment was prescribed to run for 30 years, at which point the ocean was expected to be close to steady state.

Unfortunately, ISOMIP results were never collected and compared in a formal publication. The few ISOMIP results that have been published or made publicly available (Hunter, 2003; Losch, 2008; Galton-Fenzi, 2009) suggest that melt rates as well as barotropic and overturning cir- 
culations varied between models depending on the vertical discretization and resolution of the model.

In Sect. 3, we describe the design for a second ocean MIP with ice-shelf cavities, ISOMIP+, which aims to improve upon the original ISOMIP in several ways. Bedrock and iceshelf topographies, based on MISMIP+ results, are more like those of realistic ice shelves in that the water-column thickness goes to zero at the grounding line and the topography varies in $2 \mathrm{HDs}$, rather than $1 \mathrm{HD}$. The melt parameterization and parameter choices for horizontal mixing are closer to those used in realistic applications. As opposed to forcing only at the ocean surface, ISOMIP+ uses far-field restoring throughout the water column following Holland et al. (2008) and Goldberg et al. (2012a, b), an approach more similar to those commonly used in forced regional climate experiments. Importantly, preliminary results show that restoring with a relatively warm far-field temperature profile leads to a quasi-steady state within 1 to 2 year, whereas the 30 -year ISOMIP experiments approached, but did not reach, a steady state in which the ocean was at the freezing point everywhere. Whereas ISOMIP used static ice-shelf topography, two ISOMIP+ experiments prescribe dynamic topography, allowing models to test their ability to handle moving boundaries and to see the effects that moving topography has on ocean dynamics.

ISOMIP+ will also improve upon ISOMIP in terms of organized community involvement as well as scientific developments. ISOMIP+ is expected to benefit from the organization and active community of MISOMIP, as well as the close relationship of ISOMIP + to both MISMIP+ and MISOMIP1 (through the shared experimental design and development towards coupled ice-ocean models). These factors are likely to lead a larger number of ISOMIP+ participants and formal publication of the analysis, both of which were lacking in ISOMIP.

\subsection{Coupled ice sheet-ocean modeling}

While no previous MIP has been performed with coupled ice sheet-ocean models, a number of studies have used coupled ice sheet-ocean models, most in idealized configurations. Grosfeld and Sandhäger (2004) performed offline-coupled simulations of a three-dimensional (3-D) ocean and 2-D icesheet model including dynamic calving of tabular icebergs using idealized topography based on the Filchner-Ronne Ice Shelf. Walker and Holland (2007) and Walker et al. (2008, 2009) used idealized, coupled modeling in 2-D (one horizontal and one vertical dimension) to show that warm ocean conditions and variations in ice basal sliding affected groundingline motion and ice-shelf topography on decadal timescales. Thoma et al. (2010) coupled 3-D ice-sheet and ocean models to study the dynamics of a sub-glacial lake. Determann et al. (2012) used the same models to perform ice-sheet simulations driven by melt rates computed in the ocean model, showing hysteresis following a melt perturbation applied to idealized ice-sheet topography. Goldberg et al. (2012a, b) showed results from idealized, coupled experiments spanning 250 years using four different profiles for the ambient water temperature. They showed that feedbacks between the ocean and ice-sheet components led to steepening of the ice draft near the grounding line and strong melting in a channel on the western flank of the ice shelf. Gladish et al. (2012) performed coupled simulations of an idealized ice shelf based on Petermann Glacier with the plume ocean model in 2HDs of Holland and Feltham (2006), showing the influence of channelization on total melt fluxes and melt distribution. Sergienko (2013) used the same plume model to further explore melt channels in idealized configurations. Sergienko et al. (2013) used a plume ocean model in 1HD (Jenkins, 1991) to show that ice-shelf topography is controlled by a balance between ice advection and either ice deformation or ocean melting, depending on the temperature of the ambient ocean water. Walker et al. (2013) used coupled 1-D flow-line models to explore the effects of different melt parameterizations on coupled dynamics. A study by De Rydt and Gudmundsson (2016) used a coupled ice sheetocean model in an idealized configuration similar to Pine Island Glacier to show the effect a seabed ridge can have on grounding-line stability. They also concluded that coupled ice-ocean modeling was required in their problem because commonly used parameterizations of ice-shelf basal melting differed from those produced by their ocean model by more than $40 \%$. While these individual studies have advanced our understanding of ice sheet-ocean processes, a MIP involving coupled ice sheet-ocean models is likely to improve our confidence in the models through greater understanding of the variability and the causes of differences in model results.

In Sect. 4, we describe the first Marine Ice Sheet-Ocean Model Intercomparison Project (MISOMIP1), which combines elements from MISMIP+ and ISOMIP+. In some ways, the MISOMIP1 setup is similar to that of Goldberg et al. (2012a, b) in that it includes a narrow channel with strong ice-shelf buttressing and strong far-field restoring in the ocean. MISOMIP1 differs from this previous work in having (1) steeper channel walls, meaning a stronger change in buttressing as the ice-shelf thickness changes, (2) a larger region of open ocean allowing for ocean dynamics both inside and outside the cavity, and (3) a bedrock topography with an upward-sloping region in the ice-flow direction, allowing us to investigate the possibility that thinning or other changes in the state of the ice sheet could trigger marine icesheet instability (MISI; e.g., Weertman, 1974).

\subsection{Goals of the three new MIPs}

The MIPs were designed with three main goals in mind. As in their predecessors (ISOMIP, MISMIP and MISMIP3d), the first goal of the MIPs is to provide a controlled forum for researchers to compare their model results with those from other models during model development. Furthermore, it is 
hoped that researchers will publish their MIP results and/or submit them to the relevant MIP database when they introduce new ice sheet models, ocean models with ice-shelf cavities or coupled ice sheet-ocean models. Differences between models should be investigated, understood and explained. We have endeavored to keep the MIP setups relatively simple to make them relevant and accessible to the largest possible number of potential contributors and to make them easy to duplicate, while still capturing physical processes relevant to ice sheet-ocean dynamics.

The second goal is for the three MIPs to provide a path for testing components in the process of developing a coupled ice sheet-ocean model. Within ISOMIP+, the experiments progress from static to dynamic (but prescribed) ice topography with the same goal in mind. Meeting this goal has required that all three MIPs be designed simultaneously, ensuring that they use the same bedrock topography (bathymetry) and compatible domains. Grounding-line dynamics in MISMIP+ is controlled by a melt profile that adapts to the ice topography and qualitatively mimics example results from ISOMIP + . Ice topography (both static and dynamic) for ISOMIP+ comes from example MISMIP+ results. In addition, two ISOMIP+ experiments have been designed to produce large changes in melting over a short period of time (less than a decade), mimicking the abrupt changes in the melt rate applied in MISMIP + . All three MIPs include an experiment with 100 years of ice retreat followed by 100 years of re-advance, allowing evaluation of standalone and coupled simulations of essentially the same problem.

Our third goal is that each MIP should provide a basic setup from which a large variety of parameter and process studies can usefully be performed. Each MIP setup uses idealized topography and simplifies or ignores known physics. These simplifications leave opportunities for others to study the effects of adding missing processes (e.g., a more realistic calving law, a basal hydrology model, sub-glacial meltwater runoff across the grounding line, wind stresses, seaice formation and export, tides, time-varying far-field ocean forcing). Results may be affected by parameterizations (e.g., ice sliding law, melt parameterization, mixing schemes in the ocean, equation of state) and other choices (e.g., horizontal and vertical resolution, coupling interval, ice rheology) that the community may choose to explore in more detail.

\section{MISMIP+ design}

A number of previous MIPs not specifically focused on marine ice sheets have explored model physics (EISMINT; Payne et al., 2000), provided benchmarks for higher-order stress approximations (ISMIP-HOM; Pattyn et al., 2008) and demonstrated modes of internal variability (ISMIP-HEINO; Calov et al., 2010), improving our understanding of ice-sheet models. The previous Marine Ice Sheet MIPs, MISMIP and
MISMIP3d, tested the capabilities of ice sheet models to simulate advance and retreat cycles under changes in ice softness and basal sliding, respectively, each teaching the community a great deal about the numerical behavior of ice-sheet models of various types. Nonetheless, it was clear in discussions of a follow-up intercomparison exercise that the MISMIP3d experimental design had three shortcomings as a test of 2HD marine ice sheet models. First, it started from a steady state that was invariant in the crossflow direction - that is, 1HD - meaning it did not involve significant lateral stresses. Second, the initial grounding lines of the shallow-shelf approximation (SSA) (MacAyeal et al., 1996) models were around $80 \mathrm{~km}$ downstream from the Stokes models, but the grounding line only moved about $20 \mathrm{~km}$ in the perturbation experiment. That left an obvious question entirely unanswered: in a realistic simulation with the model parameters chosen to match geometry and velocity derived from observations, and thus with prescribed initial conditions, does the SSA provide a good approximation to the Stokes model? Third, grounding-line migration was driven by changes to the basaltraction field, rather than the ice shelf melting that is thought to be the dominant driver of present-day grounding-line retreat in West Antarctica (Joughin et al., 2014; Favier et al., 2014; Seroussi et al., 2014a).

MISMIP+ has been designed to address each of these shortcomings. Regarding the first, the chosen geometry, based on Gudmundsson et al. (2012), results in strong lateral stresses that buttress the ice stream. The particular parameters chosen for MISMIP+ result in a stable grounding line crossing a retrograde slope, a configuration not possible in 1HD. Regarding the second, modelers are free to choose certain model parameters so that their initial grounding line at the center of the domain is within a tolerance of a prescribed location. Preliminary simulations with the BISICLES ice sheet model (Cornford et al., 2013) with two stress approximations that showed large differences in grounding-line position in the MISMIP3d experiments have been found to have grounding lines within a few kilometers of one another in the MISMIP+ steady state. Finally, extensive groundingline retreat is driven by sub-shelf melt rates.

\subsection{Experimental setup}

The MISMIP+ domain is a box bounded by $0 \leq x \leq$ $640 \mathrm{~km}$ and $0 \leq y \leq 80 \mathrm{~km} .^{2}$ The bedrock topography, shown in Fig. 1, is a smaller version of that given in Gudmundsson et al. (2012) and Gudmundsson (2013):

$z_{\mathrm{b}}(x, y)=\max \left[B_{x}(x)+B_{y}(y), z_{\mathrm{b}, \text { deep }}\right]$,

\footnotetext{
${ }^{2}$ The stand-alone ice sheet experiments place a calving front at $x_{\text {calve }}=640 \mathrm{~km}$. The same is true of the stand-alone ocean experiments and the coupled experiments, but the ocean domain extends to $x=800 \mathrm{~km}$.
} 
Table 1. Parameters for the MISMIP+ experiments.

\begin{tabular}{|c|c|c|}
\hline Parameter & Value & Description \\
\hline$L_{x}$ & $640 \mathrm{~km}$ & Domain length (along ice flow) \\
\hline$L_{y}$ & $80 \mathrm{~km}$ & Domain width (across ice flow) \\
\hline$B_{0}$ & $-150.0 \mathrm{~m}$ & Bedrock topography at $x=0$ \\
\hline$B_{2}$ & $-728.8 \mathrm{~m}$ & Second bedrock topography coefficient \\
\hline$B_{4}$ & $343.91 \mathrm{~m}$ & Third bedrock topography coefficient \\
\hline$B_{6}$ & $-50.57 \mathrm{~m}$ & Fourth bedrock topography coefficient \\
\hline $\bar{x}$ & $300 \mathrm{~km}$ & Characteristic along-flow length scale of the bedrock \\
\hline$f_{\mathrm{c}}$ & $4.0 \mathrm{~km}$ & Characteristic width of the side walls of the channel \\
\hline$d_{\mathrm{c}}$ & $500 \mathrm{~m}$ & Depth of the trough compared with the side walls \\
\hline$w_{\mathrm{c}}$ & $24.0 \mathrm{~km}$ & Half-width of the trough \\
\hline$z_{\mathrm{b}, \text { deep }}$ & $-720 \mathrm{~m}$ & Maximum depth of the bedrock topography \\
\hline$x_{\text {calve }}$ & $640 \mathrm{~km}$ & The location in $x$ beyond which ice is removed \\
\hline$\rho_{i}$ & $918 \mathrm{~kg} \mathrm{~m}^{-3}$ & Density of ice \\
\hline$\rho_{\mathrm{sW}}$ & $1028 \mathrm{~kg} \mathrm{~m}^{-3}$ & Density of seawater \\
\hline$\Omega$ & $0.2 \mathrm{a}^{-1}$ & Melt-rate rate factor \\
\hline$z_{0}$ & $-100 \mathrm{~m}$ & Depth above which the melt rate is zero \\
\hline$H_{\mathrm{c} 0}$ & $75 \mathrm{~m}$ & Reference ocean-cavity thickness \\
\hline$a$ & $0.3 \mathrm{ma}^{-1}$ & Accumulation rate \\
\hline$A$ & $\begin{array}{l}6.338 \times 10^{-25} \mathrm{~Pa}^{-3} \mathrm{~s}^{-1} \\
=2.0 \times 10^{-17} \mathrm{~Pa}^{-3} \mathrm{a}^{-1}\end{array}$ & Glen's law coefficient \\
\hline$n$ & 3 & Glen's law exponent \\
\hline$m$ & 3 & Friction-law exponent \\
\hline$\alpha^{2}$ & 0.5 & Coulomb law friction coefficient \\
\hline$\beta^{2}$ & $\begin{array}{l}3.160 \times 10^{6} \mathrm{Pam}^{-1 / 3} \mathrm{~s}^{1 / 3} \\
=1.0 \times 10^{4} \mathrm{~Pa} \mathrm{~m}^{-1 / 3} \mathrm{a}^{1 / 3}\end{array}$ & Power-law friction coefficient \\
\hline$g$ & $9.81 \mathrm{~m} \mathrm{~s}^{-2}$ & Acceleration of gravity \\
\hline- & $31556926 \mathrm{sa}^{-1}$ & Seconds per year (defined to have 365.2422 days) \\
\hline
\end{tabular}

$$
\begin{aligned}
& B_{x}(x)=B_{0}+B_{2} \tilde{x}^{2}+B_{4} \tilde{x}^{4}+B_{6} \tilde{x}^{6}, \\
& \tilde{x}=x / \bar{x} \\
& B_{y}(y)=\frac{d_{\mathrm{c}}}{1+e^{-2\left(y-L_{y} / 2-w_{\mathrm{c}}\right) / f_{\mathrm{c}}}} \\
& \quad+\frac{d_{\mathrm{c}}}{1+e^{2\left(y-L y / 2+w_{\mathrm{c}}\right) / f_{\mathrm{c}}}}
\end{aligned}
$$

where the parameter values used in these equations, along with several others related to the MISMIP+ experiment, are given in Table 1. As in Gudmundsson et al. (2012), there is a no-slip boundary condition at $x=0$ and free-slip boundaries at $y=0$ and $80 \mathrm{~km}$. Ice is removed from the domain beyond $x_{\text {calve }}=640 \mathrm{~km}$ but no other calving criterion is specified.

Englacial deviatoric stresses $\tau_{i j}$ are related to strain-rates $D_{i j}$ through Glen's flow law. As in previous MISMIP exercises,

$\tau_{i j}=A^{-1 / n} D_{e}^{1 / n-1} D_{i j}$,

where $n=3$. $D_{e}$ is the second scalar invariant of the strainrate, given by $2 D_{e}^{2}=D_{i j} D_{j i}$, with the usual summation convention. The ice is isothermal, with a constant rate factor $A$ independent of space, with a value determined by the participant as discussed below.

As in the previous MISMIP experiments, MISMIP+ uses a symmetry boundary condition at the ice divide, ocean pressure (up to sea level) at the ice-ocean interface, and stressfree boundary conditions at the upper surface (see Pattyn et al., 2012, 2013, for details). Where the ice is grounded, the tangential component of the basal traction $\left.\tau_{n t}\right|_{z_{\mathrm{b}}}$ is given by any of three relationships: a power law, a modified power-law relation introduced by Tsai et al. (2015), or a second modified power-law relation introduced by Schoof (2005) and explored by Gagliardini et al. (2007) and Leguy et al. (2014). Participants are free to choose any or all of these.

The power law is

$\left.\tau_{n t_{i}}\right|_{z_{\mathrm{b}}}=\beta^{2} u_{b}^{1 / m-1} u_{t_{i}} \quad(i=1,2)$,

where $u_{t_{i}}$ are the two tangential components of the velocity with magnitude $u_{b}, m=3$, and $\beta^{2}$ is a friction coefficient, which is invariant in space and with a suggested value given in Table 1 . The value of $\beta^{2}$ may be modified by the participant (see below).

The first modified law differs from the power law by preventing the basal traction from exceeding the value given by a Coulomb law, that is, a fraction of the effective pressure $N$ : 


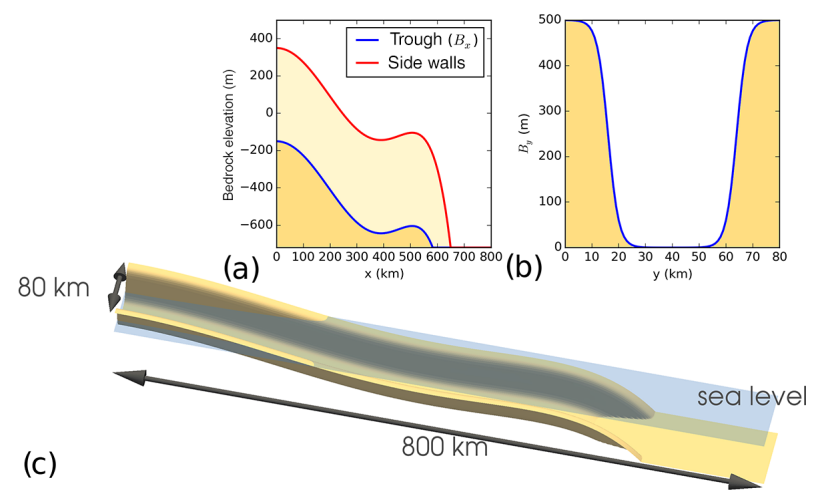

Figure 1. The bedrock topography for the three MIPs as defined by Eqs. (1)-(4). (a) The variability of the bedrock topography in the $x$ direction. The topography through the central trough, $B_{x}(x)$, is shown in blue and on the side walls is shown in red. (b) $B_{y}(y)$, the shape of the bedrock topography in the $y$ direction relative to that at the center of the trough. Note that $B_{y}(y)$ is not a transect of the topography because $B_{x}(x)$ is never equal to zero. (c) The topography in $3-\mathrm{D}$ at $1 \mathrm{~km}$ resolution. Sea level is shown in translucent blue.

$\left.\tau_{n t_{i}}\right|_{z_{\mathrm{b}}}=\min \left(\alpha^{2} N, \beta^{2} u_{b}^{1 / m}\right) u_{b}^{-1} u_{t_{i}} \quad(i=1,2)$,

where $\alpha^{2}=0.5$. $N$ should be constructed by assuming a perfect hydrological connection with the ocean so that

$N=-\sigma_{n n}-\rho_{\mathrm{sw}} g z_{\mathrm{d}}$

Hydrostatic models should approximate the normal stress $\sigma_{n n}$ in the usual way, giving

$N=\rho_{i} g\left(h-h_{f}\right)$,

where $g$ is the acceleration of gravity, $h$ is the ice thickness and

$h_{f}=\max \left(0,-\frac{\rho_{\mathrm{sw}}}{\rho_{i}} z_{\mathrm{b}}\right)$

is the flotation thickness given the bedrock elevation $z_{\mathrm{b}}$ and the reference densities of ice and seawater $\rho_{i}$ and $\rho_{\mathrm{sw}}$. Expressing the basal traction in this way ensures that it is continuous (though not differentiable) across the grounding line, but grows to $\sim 10-100 \mathrm{kPa}$ over the region $\sim 1 \mathrm{~km}$ upstream (see Fig. 2).

The second modified law has the same limits as the first modified law (the power law for large effective pressure, and the Coulomb law near the grounding line where the effective pressure approaches zero) but transitions between these limits more smoothly:

$$
\left.\tau_{n t_{i}}\right|_{z_{\mathrm{b}}}=\frac{\beta^{2} u_{b}^{1 / m} \alpha^{2} N}{\left[\beta^{2 m} u_{b}+\left(\alpha^{2} N\right)^{m}\right]^{1 / m}} u_{b}^{-1} u_{t_{i}} \quad(i=1,2) .
$$

In this form, basal traction remains continuous everywhere and differentiable everywhere except across the grounding line.

We note that Eq. (8) is a zeroth-order hydrology model that assumes connectivity to the ocean throughout the domain and is likely only valid within a few tens of kilometers of the grounding line (Leguy et al., 2014). It is likely that simulations using more realistic topography would require a more sophisticated hydrology model to produce results consistent with observations inland of the grounding line.

We prescribe that the steady-state grounding line should cross the centerline of the trough at $x=450 \pm 10 \mathrm{~km}$, ensuring that all models start from similar initial states. Participants should adjust the grounding-line position by modifying first the values of $A$ and, if necessary, the value of $\beta^{2}$ beginning with the suggested values given in Table 1 . We have adopted this approach for model initialization to be more consistent with the methods used to initialize models for real-world problems: unknown parameters or fields are determined by search or inversion techniques so that initial conditions are consistent with observations. The precise method used to adjust $A$ and/or $\beta^{2}$ and for finding the steady state is left up to the participant. Some participants will spin up their models for tens of thousands of years with different parameter values until the grounding line lies within the desired position. Others might construct a more formal optimization problem and solve it with variational methods.

A constant accumulation rate $a$, with the value given in Table 1, is applied over the entire ice surface. One of the three MISMIP+ experiments uses a parameterization of basal melting below the ice shelf, obtained by balancing the latent heat of melting with parameterized turbulent heat flux within the ocean (Jenkins et al., 2010), neglecting the heat flux into the ice:

$m_{\mathrm{i}}=\frac{\rho_{i}}{\rho_{\mathrm{fw}}} m_{\mathrm{w}}=\frac{\rho_{i} c_{\mathrm{w}} \Gamma_{\mathrm{T}}}{\rho_{\mathrm{fw}} L} u_{*}\left(T_{\mathrm{w}}-T_{\mathrm{f}}\right)$,

where $m_{\mathrm{i}}$ is the basal melt rate of ice, $m_{\mathrm{w}}$ is the same melt rate expressed in water equivalent $\left(w_{\mathrm{eq}}\right), \rho_{\mathrm{fw}}$ is the density of fresh water, $c_{\mathrm{w}}$ is the heat capacity of seawater, $L$ is the latent heat of fusion, $\Gamma_{\mathrm{T}}$ is the heat-transfer coefficient, $u_{*}$ is the ocean friction velocity and $T_{*}=\left(T_{\mathrm{w}}-T_{\mathrm{f}}\right)$ is the thermal driving, the difference between the ambient ocean water temperature $T_{\mathrm{w}}$ and the local freezing point $T_{\mathrm{f}}$.

For the purposes of model intercomparison, we have developed an ad hoc, simplified parameterization of basal melting based on results from the Parallel Ocean Program v. 2x (POP2x) using cavity shapes from a MISMIP+ simulation. The parameterization prescribes melt rates as follows:

$m_{\mathrm{i}}=\frac{\rho_{i} c_{\mathrm{W}} \Gamma_{\mathrm{T}}}{\rho_{\mathrm{fw}} L} u_{*}\left(H_{\mathrm{c}}\right) T_{*}\left(z_{\mathrm{d}}\right)$, 


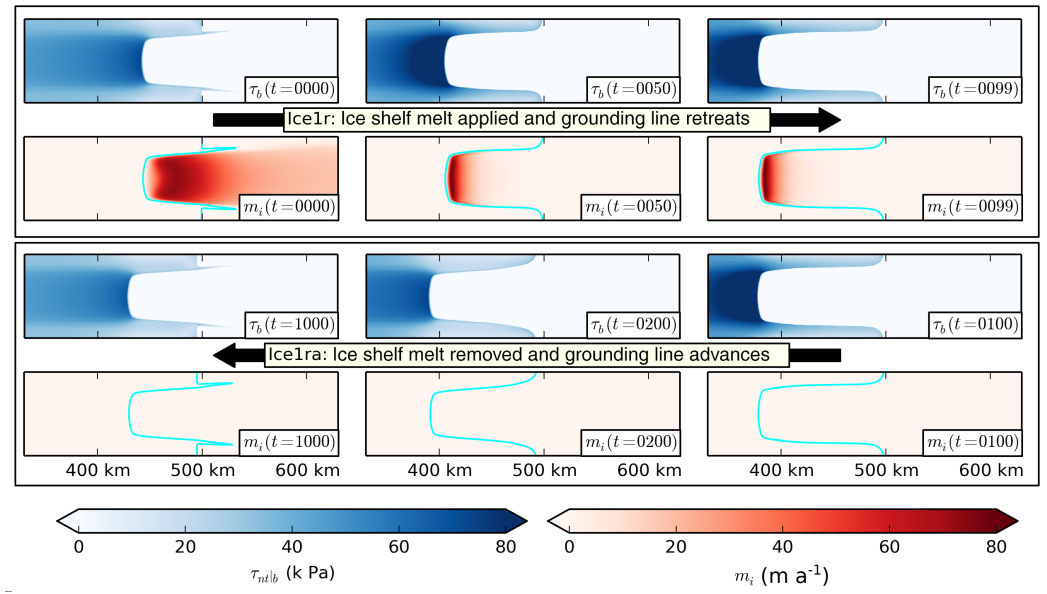

Figure 2. Evolution of the basal traction $\left.\tau_{n t}\right|_{z_{\mathrm{b}}}$ and ice shelf melt rate $m_{\mathrm{i}}$ fields during the Ice1r and Ice1ra experiments from a BISICLES run. Melt rates are applied when $0<t<100 \mathrm{a}$, causing the ice shelf to thin and grounding line to retreat. Once $t>100 \mathrm{a}$, no melt is applied, the ice shelf thickens, and the grounding line advances. The choice of the Tsai et al. (2015) traction law ensures that $\left.\tau_{n t}\right|_{z_{\mathrm{b}}}$ is continuous across the grounding line but large $\sim 1 \mathrm{~km}$ upstream. Similarly, the factor $\tanh \left(H_{\mathrm{c}} / H_{\mathrm{c} 0}\right)$ ensures that $m_{\mathrm{i}}$ is continuous across the grounding line but large $\sim 10 \mathrm{~km}$ downstream.

$u_{*}\left(H_{\mathrm{c}}\right)=u_{*, 0} \tanh \left(\frac{H_{\mathrm{c}}}{H_{\mathrm{c} 0}}\right)$

$T_{*}\left(z_{\mathrm{d}}\right)=\frac{T_{*, 0}}{z_{\text {ref }}} \max \left(z_{0}-z_{\mathrm{d}}, 0\right)$,

$H_{\mathrm{c}}=z_{\mathrm{d}}-z_{\mathrm{b}}$,

where $z_{\mathrm{d}}$ is the elevation of the ice-ocean interface (ice draft), $H_{\mathrm{c}}$ is the water-column thickness, and $u_{*, 0}, H_{\mathrm{c} 0}, T_{*, 0}$ and $z_{\text {ref }}$ are fitting constants.

The POP2x results suggest that the friction velocity $u_{*}$ increases linearly near the grounding line (for small $H_{\mathrm{c}}$ ) but saturates to a nearly constant value when the ocean-cavity thickness exceeds a threshold thickness $H_{\mathrm{c} 0}=75 \mathrm{~m}$. GaltonFenzi (2009) also showed that melt rates tend to approach zero near the grounding line in a number of experiments, though he found that glacial meltwater fluxes can lead to increased melt rates immediately adjacent to the grounding line. Glacial meltwater fluxes are neglected here. In their idealized simulations studying the behavior of meltwater impeded by a bathymetric ridge, De Rydt et al. (2014) saw a similar tapering of the melt rate near the grounding line. It should be noted that melt rates near grounding lines are not well constrained by observations and that ocean models may have particular difficulty in these regions. Therefore, the dependence upon water-column thickness should be treated as an ad hoc formulation for the purpose of a model intercomparison and not necessarily as a realistic representation of melting near grounding lines.

The POP2x simulations used to calibrate the parameterization had a temperature profile that increased linearly with depth (similar to the profiles described in Sect. 3.1.3), leading to a thermal driving that also increased approximately linearly with depth. Thermal driving, and therefore melting, reached zero at a depth $z_{0} \sim-100 \mathrm{~m}$. Though the simulations showed some freezing above this depth, our parameterization assumes for simplicity that no melting or freezing occurs at depths shallower than $z_{0} \equiv-100 \mathrm{~m}$.

We simplify $m_{\mathrm{i}}$ by lumping various constants and coefficients from Eqs. (13)-(15) into a single coefficient $\Omega$ :

$m_{\mathrm{i}}=\Omega \tanh \left(\frac{H_{\mathrm{c}}}{H_{\mathrm{c} 0}}\right) \max \left(z_{0}-z_{\mathrm{d}}, 0\right)$.

Fig. 3 shows a schematic of the ice shelf, labeling the various depths and thicknesses involved in the melt parameterization, as well as the melt rate as a function of $z_{\mathrm{d}}$ and $H_{\mathrm{c}}$. Again, the parameter values are given in Table 1 . The coefficient $\Omega$ has been given a value of $0.2 \mathrm{a}^{-1}$, corresponding to a maximum ambient ocean temperature $\sim 1.0^{\circ} \mathrm{C}$, which leads to a melt rate with a maximum value of $m_{\mathrm{i}} \approx 75 \mathrm{ma}^{-1}$ of ice near the grounding line of the BISICLES initial condition (see Fig. 2). We reiterate that the formulation given by Eq. (17) is an ad hoc parameterization appropriate only for this intercomparison and not appropriate for other geometries, ocean ambient temperatures, etc. The melt parameterization is missing known physics such as dependence on the slope of the ice draft (Goldberg et al., 2012a) and superlinear dependence on ambient ocean temperature (Holland et al., 2008).

\subsection{Experiments}

MISMIP + consists of three experiments with different melt rates. Each experiment is initialized with $m_{\mathrm{i}}=0$ (no melting), and should begin with a stable grounding line crossing the center of the channel on the retrograde slope around $x=450 \pm 10 \mathrm{~km}$. Stable in this case means that the ice sheet 


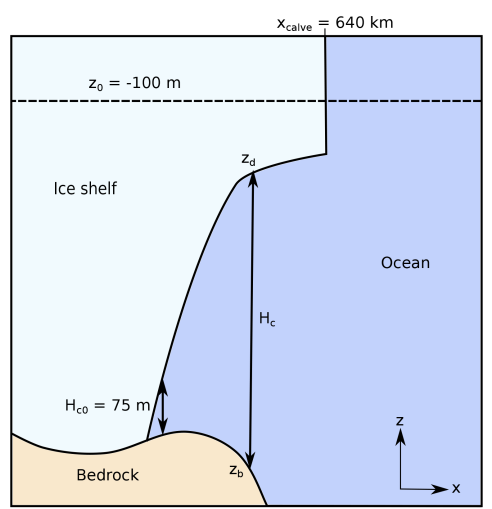

(a)

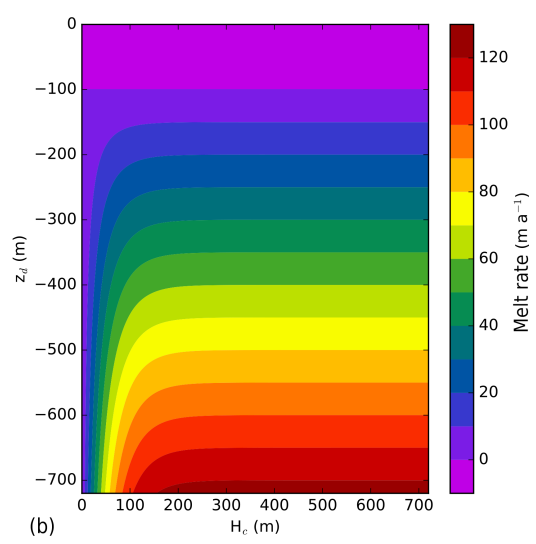

Figure 3. (a) A schematic showing the ice draft $\left(z_{\mathrm{d}}\right)$, the bedrock elevation $\left(z_{\mathrm{b}}\right)$, the cutoff depth $\left(z_{0}\right)$ above which the melt rate is zero, the ocean column thickness $\left(H_{\mathrm{c}}\right)$ and the reference thickness $H_{\mathrm{c} 0}$. (b) The melt parameterization given by Eq. (17). Melting increases linearly with decreasing $z_{\mathrm{d}}$ below $z_{0}$ and is independent of $H_{\mathrm{c}}$ when the ocean column is thick and zero near the grounding line as the ocean column thins.

thickness and the grounding-line position is permitted to fluctuate, but any fluctuations should average to zero over time, and should be of low amplitude compared to the response to perturbations. Preliminary experiments indicate that, starting from a uniform thickness of $100 \mathrm{~m}$, a stable state is found after around $20000 \mathrm{a}$. One experiment (Ice0) is simply a control, where the melt rate is maintained at $m_{\mathrm{i}}=0$ for 100 years, while the other two (Ice1 and Ice2) are intended to study the response to substantial ice shelf ablation.

Experiment Ice1 is divided into several parts, all beginning with Ice1r, where the melt rate given in Eq. (17) is applied from $t=0$ to $t=100 \mathrm{a}$, and is expected to produce thinning of the ice shelf, a loss of buttressing, and groundingline retreat. Ice1ra starts from the state computed at the end of the Ice1r simulation and runs at least until $t=200 \mathrm{a}$, and optionally until $t=1000 \mathrm{a}$, with no melting, so that the ice shelf thickens, buttressing is restored and the grounding line advances. Preliminary simulations have shown that the grounding-line position does not reach its initial steady state within even 1000 years. Finally, Ice1rr is optional and continues Ice1r, with the melt rate of Eq. (17), until $t=1000 \mathrm{a}$. Figure 2 shows example basal-traction and melt-rate fields calculated at several points during the Ice1r and Ice1ra experiments.

Experiment Ice 2 is structured in the same way as Ice1, but a different melt rate is applied. The Ice1 melt rate adjusts to pursue the grounding line as it retreats, preventing the formation of a substantive ice shelf. In contrast, Ice $2 \mathrm{r}$ prescribes a sub ice-shelf melt-rate of $100 \mathrm{~m} \mathrm{a}^{-1}$, where $x>480 \mathrm{~km}$ and no melt elsewhere from $t=0$ to $t=100 \mathrm{a}$, resulting in substantial loss of ice concentrated away from the grounding line, as in a sequence of extensive calving events ${ }^{3}$. Preliminary calculations show that the grounding line retreats for

\footnotetext{
${ }^{3}$ An alternative would be to have participants move the calving front upstream in Ice2r and allow it to advance in Ice2ra. We chose
}

more than $20 \mathrm{~km}$ but begins to stabilize as a thick ice shelf forms in its wake. Ice2ra takes the endpoint of the Ice2r experiment as its initial state, and evolves the ice sheet with no melting until $t=200 \mathrm{a}$ and optionally until $t=1000 \mathrm{a}$, while Ice $2 \mathrm{rr}$ is optional and continues Ice $2 \mathrm{r}$ to $t=1000 \mathrm{a}$.

As an example, Fig. 4 plots grounded area against time for all of the MISMIP+ experiments carried out with BISICLES using SSA. We emphasize that the example results shown in this figure are not intended as a benchmark for other simulations, but simply to demonstrate generally what type of behavior might be expected in each experiment. Table 2 gives a brief summary of the MISMIP+ experiments, as well as those from the other two MIPs.

Figure 5 shows the sensitivity of the BISICLES Ice1r results to various choices of basal traction, stress approximation, and values of $A$. Results are nearly insensitive to the differences between the basal-traction parameterizations of Tsai et al. (2015) and Schoof (2005), and also to differences between two stress approximations, SSA and SSA* (Schoof and Hindmarsh, 2010). However, the simulations with the basal traction of Weertman (1974) show a significant difference in both the initial grounded area and the rate of retreat compared with the other parameterizations. Furthermore, even when $A$ is adjusted so that the initial grounding-line position (and therefore the grounded area) is in agreement with the other configurations, the rate of retreat remains significantly slower than for the other parameterizations.

\subsection{Requested output}

MISMIP+ requested output is divided into compulsory and optional parts. The compulsory components will be used to

a melt-rate perturbation instead because it requires the same model capabilities as Ice1. 
Table 2. List of the MISMIP+, ISOMIP+ and MISOMIP1 experiments.

\begin{tabular}{|c|c|c|}
\hline MIP & Experiment & Description \\
\hline MISMIP+ & Ice 0 & 100-year control simulation with no melting \\
\hline MISMIP+ & Ice1r & 100-year run with melt-induced retreat \\
\hline MISMIP+ & Ice1ra & $\begin{array}{l}100 \text {-year (or optionally up to } 900 \text {-year) simulation } \\
\text { from end of Ice1r with no melting }\end{array}$ \\
\hline MISMIP+ & Ice1rr & Continue Ice1r for a further 900 years (optional) \\
\hline MISMIP+ & Ice $2 r$ & 100-year “calving-event" simulation \\
\hline MISMIP+ & Ice2ra & $\begin{array}{l}100 \text {-year (or optionally up to } 900 \text {-year) simulation } \\
\text { from end of Ice } 2 r \text { with no melting }\end{array}$ \\
\hline MISMIP+ & Ice $2 \mathrm{rr}$ & Continue Ice 2 r for a further 900 years (optional) \\
\hline ISOMIP+ & Ocean 0 & $\begin{array}{l}\text { 1-year run with static topography, WARM initial } \\
\text { conditions and WARM forcing }\end{array}$ \\
\hline ISOMIP+ & Ocean1 & $\begin{array}{l}20 \text {-year run with static topography, COLD initial } \\
\text { conditions and WARM forcing }\end{array}$ \\
\hline ISOMIP+ & Ocean2 & $\begin{array}{l}\text { 20-year run with static topography, WARM initial } \\
\text { conditions and COLD forcing }\end{array}$ \\
\hline ISOMIP+ & Ocean3 & $\begin{array}{l}\text { 100-year run with dynamic topography, WARM initial } \\
\text { conditions and WARM forcing }\end{array}$ \\
\hline ISOMIP+ & Ocean4 & $\begin{array}{l}\text { 100-year run with dynamic topography, COLD initial } \\
\text { conditions and COLD forcing }\end{array}$ \\
\hline MISOMIP1 & IceOcean1r & $\begin{array}{l}\text { 100-year coupled run with no dynamic calving, } \\
\text { COLD initial conditions and WARM forcing }\end{array}$ \\
\hline MISOMIP1 & IceOcean1ra & $\begin{array}{l}\text { 100-year coupled run from end of IceOcean } 1 \mathrm{r} \text { with } \\
\text { no dynamic calving and COLD forcing }\end{array}$ \\
\hline MISOMIP1 & IceOcean2r & $\begin{array}{l}\text { Optional: } 100 \text {-year coupled run with dynamic calving, } \\
\text { COLD initial conditions and WARM forcing }\end{array}$ \\
\hline MISOMIP1 & IceOcean2ra & $\begin{array}{l}\text { Optional: } 100 \text {-year coupled run from end of } \\
\text { IceOcean } 2 r \text { with dynamic calving and COLD forcing }\end{array}$ \\
\hline
\end{tabular}

write an analysis paper, along the lines of the MISMIP3d paper (Pattyn et al., 2013). The optional data will be included with the compulsory data in an open-access database.

Participants are required to supply point data at the grounding line, along the same lines as MISMIP3d, as well as integrated quantities such as volume above flotation, at set times throughout the experiments. Data should be stored in a single NetCDF 4 file for each experiment with the file-naming convention of [expt]_[MODEL].nc, where [expt] is an experiment name from Table 2 and [MODEL] is a unique identifier for the participant. For the core experiments, where $0 \leq t \leq 200$, data should be provided every 10 years starting from $t=0$, while for the optional extensions, data should be provided every 100 years starting from $t=200$. Since the length of the grounding line varies over time, we expect that the number of point data required to describe it will vary over time in all models. It will be left to each participant to decide how to determine location of the grounding-line points (e.g., taking cell edges between grounded and floating regions or performing sub-grid-scale interpolation).
We ask participants to use the variable and dimension names given in bold and units given in square brackets as follows:

- nPointGL: an unlimited dimension - a netCDF4 feature that allows nPointGL to be decided as the data are written;

- nTime: a fixed dimension;

- time(nTime) [a]: the time in years since the beginning of the experiment;

- iceVolume(nTime) $\left[\mathrm{m}^{3}\right], \quad$ iceVAF(nTime) $\quad\left[\mathrm{m}^{3}\right]$, groundedArea(nTime) $\left[\mathrm{m}^{2}\right]$ : the ice volume, volume above flotation, and the grounded area, integrated over the domain;

- xGL(nPointGL,nTime), yGL(nPointGL,nTime) [m]: the $x$ and $y$ coordinates of a given point on the grounding line;

- iceThicknessGL(nPointGL,nTime) [m]: ice thickness at the grounding line; 


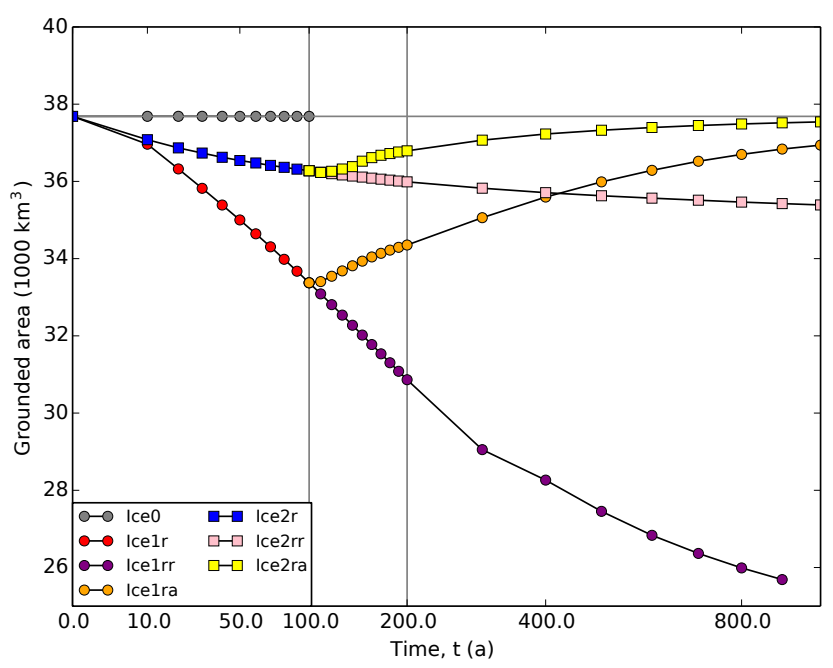

Figure 4. Grounded area plotted against time for the MISMIP+ experiments, computed using BISICLES with the SSA and the Tsai et al. (2015) basal traction. The Ice0, Ice1r and Ice2r experiments all start from steady-state, and apply either zero melt (Ice0) or melt rates derived from simple formulae (Ice1r and Ice2r) from $t=0$ to $t=100 \mathrm{a}$. Following on from Ice1r, the Ice1ra and Ice1rr experiments evolve the ice sheet until at least $t=200 \mathrm{a}$ and optionally to $t=1000 \mathrm{a}$, with the melt rate set to zero in Ice1ra and derived from the same formula as Ice1r in Ice1rr. Ice2ra and Ice2rr follow on from Ice $2 r$ in a similar fashion.

- uBaseGL(nPointGL,nTime), vBaseGL(nPointGL,nTime) $\left[\mathrm{ma}^{-1}\right]$ : the $x$ and $y$ components of the basal velocity;

- uSurfaceGL(nPointGL,nTime), vSurfaceGL(nPointGL,nTime) $\left[\mathrm{ma}^{-1}\right]$ : the $x$ and $y$ components of the surface velocity;

- uMeanGL(nPointGL,nTime), vMeanGL(nPointGL,nTime) $\left[\mathrm{ma}^{-1}\right]$ : the $x$ and $y$ components of the vertical mean of the velocity.

Since the number of grounding-line points $n(t)$ will vary over time, most of the slices $\mathbf{x G L}(:, t)$ will contain missing values, which should be filled with the default value NC_FILL_FLOAT. In Python, C and Fortran this can be achieved by writing data for each time step in turn into the first $n(t)$ elements of the slice $\mathbf{x G L}(:, t)$. At the same time, the unlimited dimension nPointGL will be automatically adjusted by the netCDF library routines to the maximum value of $n(t)$. Two python programs are included in the Supplement: write_example.py creates a netcdf file given data in the MISMIP3d text file format, and plot_example.py reads example netcdf files, constructs a plot like Fig. 4, and takes advantage of numpy's masked array class to show the changing shape of the grounding line.

All submissions should include a brief model description, in a pdf file, which summarizes the stress approximation

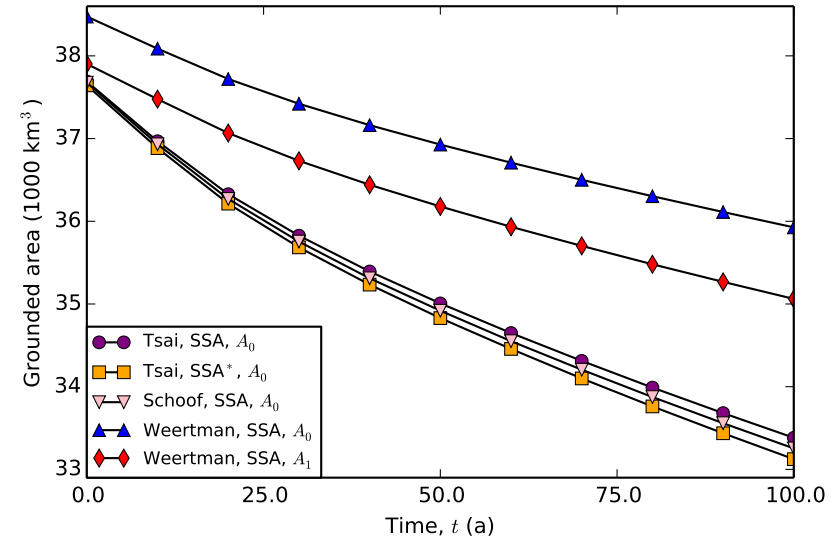

Figure 5. BISICLES parameter sensitivity in the MISMIP+ Ice1r experiment. The Tsai et al. (2015) and Schoof (2005) basal-traction laws lead to similar initial states and rates of retreat, as do the SSA and $\mathrm{SSA}^{*}$ stress approximations, given the same rate factor $A_{0}=$ $2.0 \times 10^{-17} \mathrm{~Pa}^{-3} \mathrm{a}^{-1}$. On the other hand the, the Weertman basaltraction law results in a grounding line some way upstream given the same rate factor, a closer grounding line when the rate factor is increased to $A_{1}=2.2 \times 10^{-17} \mathrm{~Pa}^{-3} \mathrm{a}^{-1}$, and a far slower rate of retreat in either case.

and parameters used, and evidence that simulations are adequately resolved. The model summary should be an enumerated list, indicating

1. model: the name of the model (e.g., BISICLES), with a citation if available;

2. repository: a link to the repository where the model can be downloaded (if public) and specific tag, branch or revision (if available);

3. englacial stresses: the stress approximation and coefficients (e.g., SSA, $A=2.0 \times 10^{-17} \mathrm{~Pa}^{-3} \mathrm{a}^{-1}$ );

4. basal traction: the choice of law and coefficients, e.g., $\left|\tau_{b}\right|=\beta^{2} u_{b}^{1 / 3}, \beta^{2}=10^{4} \mathrm{Pam}^{-1 / 3} \mathrm{a}^{1 / 3} ;$

5. space discretization: e.g., finite volume, adaptive nonuniform grid, square cells $0.25 \mathrm{~km}<\Delta x<4.0 \mathrm{~km}$;

6. time discretization: e.g., Piecewise Parabolic Method, explicit, $\Delta t<\Delta x /(4|u|)$;

7. grounding line: any special treatment of the grounding line, e.g., one-sided differences of surface elevation;

8. MISMIP3d name: the name of the model in MISMIP3d, with any relevant differences, e.g., DMA6 (different mesh resolution).

Evidence that the submissions are adequately resolved will vary from model to model. Typically, models should simply carry out a convergence study of experiment Ice1r and 
Table 3. Parameters shared between all five ISOMIP+ experiments.

\begin{tabular}{lll}
\hline Parameter & Value & Description \\
\hline$x_{0}$ & $320 \mathrm{~km}$ & Southern boundary of the domain \\
$y_{0}$ & 0 & Eastern boundary of the domain \\
$L_{x}$ & $480 \mathrm{~km}$ & Domain length (south to north, along ice flow) \\
$L_{y}$ & $80 \mathrm{~km}$ & Domain width (east to west, across ice flow) \\
$H_{\text {calve }}$ & $100 \mathrm{~m}$ & Minimum thickness of ice, below which it is removed \\
$\theta_{\mathrm{c}}$ & $75^{\circ} \mathrm{S}$ & Latitude of the center of the domain \\
$\gamma_{0}$ & $10 \mathrm{days}$ & Restoring decay rate at the northern boundary \\
$x_{r 0}$ & $790 \mathrm{~km}$ & Southern edge of the restoring region \\
$x_{r 1}$ & $800 \mathrm{~km}$ & Northern edge of the restoring region \\
\hline
\end{tabular}

Ice1ra, showing that the grounding-line shape and positions at the start and end of Ice1r and the volume-above-flotation curves throughout the experiments converge with mesh refinement and differ by a fraction at the finer resolutions. An example model description is included in the Supplement.

Optionally, participants can add further high-volume data to their NetCDF file. These consist of several fields on a uniform $1 \mathrm{~km}$ grid, and are the same fields requested in the coupled IceOcean experiments. They will not be used in the MISMIP+ analysis paper, but will be freely available once the analysis is published. The optional fields are

- nx,ny. fixed dimensions, cell-centered points on an $800 \times 80$ grid of $1 \mathrm{~km}$ squares;

- $\mathbf{x}(\mathrm{nx})$ and $\mathbf{y}(\mathrm{ny})[\mathrm{m}]$ cell centers of the output grid as vectors. The grid spacing is $1 \mathrm{~km}$;

- iceThickness(nTime,ny,nx) [m] ice thickness;

- upperSurface(nTime,ny,nx), lowerSurface(nTime,ny,nx) [m] upper and lower surface elevation;

- basalMassBalance(nTime,ny,nx) $\left[\mathrm{ma}^{-1}\right]$ of ice (not water equivalent) basal mass balance (melt rate), positive for melting and negative for freezing;

- groundedMask(nTime,ny,nx), floatingMask(nTime,ny,nx) the fraction of grounded or floating ice in a given cell;

- basalTractionMagnitude(nTime,ny,nx), $[\mathrm{Pa}]$ the magnitude of the tangential basal-traction field $\left|\tau_{n t}\right|_{\mathrm{b}} \mid$;

- uBase(nTime,ny,nx), vBase(nTime,ny,nx) $\left[\mathrm{ma}^{-1}\right] x$ and $y$ components of the basal velocity;

- uSurface(nTime,ny,nx), $\quad$ vSurface(nTime,ny,nx) $\left[\mathrm{ma}^{-1}\right] x$ and $y$ components of the surface velocity;

- uMean(nTime,ny,nx), vMean(nTime,ny,nx) $\left[\mathrm{ma}^{-1}\right] x$ and $y$ components of the vertical mean of the velocity.

\section{ISOMIP+ design}

The ISOMIP+ experiments have been designed to make a number of improvements on the original ISOMIP experiments. Whereas ISOMIP used highly idealized topography (the ocean column at the grounding line was $200 \mathrm{~m}$ thick, the ice draft sloped linearly with latitude and was invariant with longitude, and the bedrock was perfectly flat), ISOMIP+ makes use of relatively complex topography from MISMIP+ BISICLES simulations, including an ocean cavity that reaches zero thickness at the grounding line. Where ISOMIP uses a velocity-independent, two-equation formulation of the melt boundary conditions, ISOMIP+ uses the velocity-dependent three-equation formulation (e.g., Holland and Jenkins, 1999; Jenkins et al., 2010) more commonly used in realistic model configurations. ISOMIP specified $\sim 10 \mathrm{~km}$ resolution, too coarse to resolve the $9 \mathrm{~km}$ Rossby radius of deformation (Grosfeld et al., 1997), and large values of the horizontal viscosity and diffusivities, leading to a laminar flow that evolved toward steady state without eddies or other fluctuations. In contrast, ISOMIP+ runs will typically use smaller horizontal viscosity and diffusivities and higher resolution $(\sim 2 \mathrm{~km})$, allowing for mesoscale eddies and unsteady flow. A smaller computational domain makes the experiments computationally feasible despite the higher resolution. ISOMIP+ should provide more appropriate test cases than the original ISOMIP for realistic experiments, particularly for those focused on the Amundsen Sea region of WAIS.

ISOMIP+ prescribes five experiments, Ocean0 through Ocean4. Ocean0-2 have fixed topography while Ocean3-4 have prescribed, evolving ice topography. The experiments are summarized in Table 2.

\subsection{Shared setup across the five experiments}

We request that ISOMIP+ participants perform each experiment once at a common resolution and with a common set of parameters (hereafter, the COM configuration), and once at a typical resolution and with typical parameters they would use for a realistic problem (hereafter, the TYP configuration). TYP allows participants to choose resolution, parameters and 
parameterizations typical to each model as it is most often used. We ask participants who do not feel they have time to perform both the COM and TYP experiments to prioritize the COM experiments.

The purpose of COM is to produce results that can be more easily intercompared. We would like to discover the consequences of certain modeling choices (e.g., the horizontal and vertical discretization), keeping as many aspects of the configuration as possible common to all participating models. TYP will allow us to compare the results of models as they are configured for real problems and to better understand the diversity of results that different modeling choices produce. Given that there is currently no "right" answer to the ISOMIP+ experiments - there are no observations or exact mathematical solutions with which to compare - the spread in TYP model results is expected to give us insight into how uncertainties reflected in parameter choices affect model solutions.

Parameters general to both COM and TYP runs are given in Table 3, while parameters specific to the COM runs are given in Table 4.

\subsubsection{Domain and topography}

The ISOMIP+ domain is a Cartesian box bounded by $320 \mathrm{~km} \leq x \leq 800 \mathrm{~km}$ and $0 \leq y \leq 80 \mathrm{~km}$, overlapping with the right half of the MISMIP+ domain. To aid in describing features within the domain, we define positive $x$ as pointing north (the flow direction of most Antarctic ice shelves) and positive $y$ as pointing west. These directions have no dynamic consequences. A region of open ocean extends beyond the edge of the MISMIP+ calving front (which is not allowed to advance beyond $x_{\text {calve }}=640 \mathrm{~km}$ ) on the northern side of the domain. The southern boundary has been placed far enough south to accommodate the retreated ice-shelf topography used in Ocean2, which is also the most retreated state in Ocean3 and Ocean4.

The Coriolis parameter requires latitude to be defined over the domain. We prescribe an $f$ plane configuration (Gill, 1982, Chapt. 7; Pond and Pickard, 1983, Chapt. 6) at $75^{\circ} \mathrm{S}$ latitude, although models that do not support an $f$ plane should vary latitude in the $x$ direction with $75^{\circ} \mathrm{S}$ at the center of the domain (and mention this in the description pdf that participants will submit with their results). Longitude plays no role in the dynamics, and can be defined arbitrarily.

The bathymetry is the same as in Eq. (1). Because the icedraft topography is derived from ice-sheet model results, it cannot be described by an analytic function. Instead, both the topography used for Ocean0-2 and the snapshots used to produce the dynamic topography for Ocean3-4 come from MISMIP+ BISICLES results, and are available in NetCDF format for download (Cornford and Asay-Davis, 2016). The topography data come from the BISICLES model (Cornford et al., 2013) in the SSA configuration. The topography is provided on a uniform $1 \mathrm{~km}$ grid so that participants can process the data as they require. We prescribe a slightly coarser resolution, $2 \mathrm{~km}$, for COM runs, since POP2x simulations indicated that $1 \mathrm{~km}$ resolution would be too time consuming and resource intensive for some participants in the MIP. For both COM and TYP runs, participants are expected to interpolate the ice-sheet topography to the ocean grid as part of whatever processing is required to make the data ocean-model friendly. To aid later analysis of the effect these modifications to the topography might have on the results, participants are asked to provide a description of their model specific modifications, e.g., smoothing, determining regions of land, open ocean and ice-shelf cavity, and expanding the water column to a minimum thickness. The calving criterion, described below, should also be applied during this processing step.

Some participating ocean models require a surface pressure rather than the ice draft as the upper boundary condition. These models are free to compute the ice thickness from the ice surface elevation and ice draft provided in the input geometry, and multiply these by $\rho_{i} g$ to get a pressure. Equivalently, the pressure can be derived from the ice draft as $p_{z_{\mathrm{d}}}=-\rho_{\mathrm{sw}} g z_{\mathrm{d}}$. The elevation of the ice-ocean interface in the model will differ slightly from the prescribed $z_{\mathrm{d}}$ because of the dynamic pressure and variations in the ocean density, but the slight variation in topography across models is not expected to contribute significantly to differences between model results.

\subsubsection{Calving}

The MISMIP + experiments explicitly exclude a dynamic calving criterion, allowing the ice to become arbitrarily thin without calving. We felt that it was important that ISOMIP+ include the effects of a cliff-like calving front so that participating ocean models will be required to demonstrate their ability to handle advance and retreat of this jump in topography. We feel that this is important because ocean models will require this capability to handle real-world problems with dynamic calving fronts. Therefore, we prescribe a calving criterion on the MISMIP+ topography used in ISOMIP+: Ice thinner than $H_{\text {calve }}=100 \mathrm{~m}$ (equivalent to an ice draft above $\sim-90 \mathrm{~m}$ ) is considered to have calved and the ice draft is set to zero. This threshold was chosen to eliminate the thinnest ice on eastern and western flanks of the ice tongue while maintaining the tongue itself. A thicker threshold, more consistent with typical Antarctic ice shelves, would eliminate large portions of the ice shelf during retreat and make analysis of the evolving melt-rate field more challenging.

Ocean 1 and Ocean 2 have stationary topography, so the calving criterion needs to be applied only once when setting up the model domain. Ocean3 and Ocean4 have dynamic topography so it will be necessary to apply calving as the topography is interpolated in time. To accommodate models that wish to interpolate the MISMIP+ topography in time for Ocean3 and Ocean4 (see Sects. 3.2.4 and 3.2.5), we have not applied the calving criterion to the provided topography. 
Table 4. Parameters recommended for the common (COM) experiments.

\begin{tabular}{|c|c|c|}
\hline Parameter & Value & Description \\
\hline$\Delta x=\Delta y$ & $2 \mathrm{~km}$ & Horizontal resolution \\
\hline$c_{\mathrm{W}}$ & $3974 \mathrm{~J}^{\circ} \mathrm{C}^{-1} \mathrm{~kg}^{-1}$ & Specific heat capacity of seawater \\
\hline$L$ & $3.34 \times 10^{5} \mathrm{~J} \mathrm{~kg}^{-1}$ & Latent heat of fusion of ice \\
\hline$\lambda_{1}$ & $-0.0573^{\circ} \mathrm{CPSU}^{-1}$ & Liquidus slope \\
\hline$\lambda_{2}$ & $0.0832^{\circ} \mathrm{C}$ & Liquidus intercept \\
\hline$\lambda_{3}$ & $-7.53 \times 10^{-8}{ }^{\circ} \mathrm{CPa}^{-1}$ & Liquidus pressure coefficient \\
\hline$\Gamma_{\mathrm{T}}$ & model specific & Nondimensional heat-transfer coefficient \\
\hline$\Gamma_{\mathrm{S}}$ & $\Gamma_{\mathrm{T}} / 35$ & Nondimensional salt-transfer coefficient \\
\hline$C_{\mathrm{D}, \text { top }}$ & $2.5 \times 10^{-3}$ & Top drag coefficient \\
\hline$C_{\mathrm{D}, \text { bot }}$ & $2.5 \times 10^{-3}$ & Bottom drag coefficient \\
\hline$u_{\text {tidal }}$ & $0.01 \mathrm{~m} \mathrm{~s}^{-1}$ & RMS velocity associated with tides \\
\hline$\kappa_{i}$ & 0 & Heat diffusivity into ice (perfectly insulating) \\
\hline$v_{\text {unstab }}$ & $0.1 \mathrm{~m}^{2} \mathrm{~s}^{-1}$ & Convective vertical viscosity \\
\hline$\kappa_{\text {unstab }}$ & $0.1 \mathrm{~m}^{2} \mathrm{~s}^{-1}$ & Convective vertical diffusivity \\
\hline$v_{\text {stab }}$ & $1 \times 10^{-3} \mathrm{~m}^{2} \mathrm{~s}^{-1}$ & Stable vertical eddy viscosity \\
\hline$\kappa_{\text {stab }}$ & $5 \times 10^{-5} \mathrm{~m}^{2} \mathrm{~s}^{-1}$ & Stable vertical eddy diffusivity \\
\hline$v_{\mathrm{H}}$ & $6.0 \mathrm{~m}^{2} \mathrm{~s}^{-1}$ & Horizontal eddy viscosity \\
\hline$\kappa_{\mathrm{H}}$ & $1.0 \mathrm{~m}^{2} \mathrm{~s}^{-1}$ & Horizontal eddy diffusivity \\
\hline$\rho_{\mathrm{fw}}$ & $1000 \mathrm{~kg} \mathrm{~m}^{-3}$ & Density of fresh water \\
\hline$\rho_{\mathrm{sw}}$ & $1028 \mathrm{~kg} \mathrm{~m}^{-3}$ & Reference density of seawater \\
\hline$T_{\text {ref }}$ & $-1^{\circ} \mathrm{C}$ & Reference potential temperature for linear equation of state (EOS) \\
\hline$S_{\text {ref }}$ & 34.2 PSU & Reference salinity for linear EOS \\
\hline$\rho_{\text {ref }}$ & $1027.51 \mathrm{~kg} \mathrm{~m}^{-3}$ & In situ density for linear EOS \\
\hline$\alpha_{\text {lin }}$ & $3.733 \times 10^{-5 \circ} \mathrm{C}^{-1}$ & Thermal expansion coefficient for linear EOS \\
\hline$\beta_{\text {lin }}$ & $7.843 \times 10^{-4} \mathrm{PSU}^{-1}$ & Salinity contraction coefficient for linear EOS \\
\hline
\end{tabular}

Calving must be applied as part of setting up the topography. This prevents the cliff face at the calving front from pinching off vertically over the course of a year (because of interpolation between large thickness and zero thickness) instead of advancing or retreating horizontally in time. Models that do not support a sheer calving face or which update the ice topography at each time step will likely need to smooth the calving face over several horizontal grid cells and/or to relax to the new geometry gradually over time. In such cases, it is suggested that participants interpolate the geometry in time, then apply the calving criterion, and finally apply whatever smoothing or relaxation is required. This way, the (smoothed) calving front is expected to move relatively continuously in the horizontal direction, rather than abruptly jumping to the new location each year as the ice between the old and new calving fronts thins to zero.

Calved ice is simply removed from the domain, and contributes no freshwater flux to the ocean. We feel this is justified partly because it keeps the problem as simple as possible and partly because an Antarctic iceberg would be transported out of the ISOMIP+ domain in a matter of months, meaning most meltwater would be deposited elsewhere in a real-world problem.

\subsubsection{Forcing}

There is no forcing at the surface of the open ocean (i.e., no atmospheric or sea-ice fluxes) in any of the experiments. Aside from melt fluxes under the ice shelf, the only forcing is via 3-D restoring within $10 \mathrm{~km}$ of the northern boundary. In the restoring region, potential temperature and salinity are restored to prescribed profiles with the following tendencies:

$$
\begin{aligned}
& \left.\frac{\partial T}{\partial t}\right|_{\text {res }}=-\gamma(x)\left[T-T_{\text {res }}(z)\right], \\
& \left.\frac{\partial S}{\partial t}\right|_{\text {res }}=-\gamma(x)\left[S-S_{\text {res }}(z)\right],
\end{aligned}
$$

where $T_{\text {res }}(z)$ and $S_{\text {res }}(z)$ are the restoring profiles for potential temperature and salinity, respectively, and $\gamma(x)$ is the decay rate, which increases linearly from zero (no restoring) at $x_{r 0}=790 \mathrm{~km}$ to $\gamma_{0}=10$ days $^{-1}$ at the northern boundary, $x_{r 1}=800 \mathrm{~km}$ :

$\gamma(x)=\gamma_{0} \max \left(0, \frac{x-x_{r 0}}{x_{r 1}-x_{r 0}}\right)$.

The relatively fast restoring rate, corresponding to a restoring timescale of 0.1 days, was chosen following Goldberg et al. (2012a, b). 

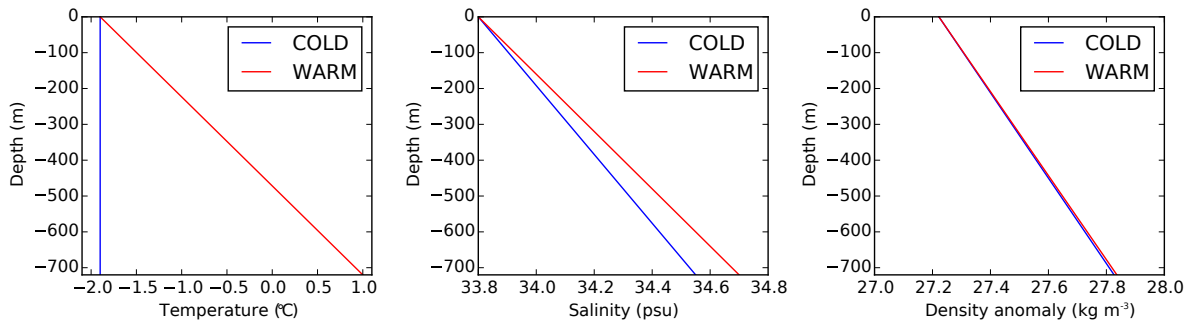

Figure 6. WARM and COLD temperature, salinity and density profiles used in all five ISOMIP+ experiments. In Ocean1, the COLD profile specifies the initial condition and the WARM profile is used in the restoring, while in Ocean 2 the profiles are switched. Ocean 3 uses both WARM initial conditions and restoring whereas Ocean4 uses both COLD initial conditions and restoring. The WARM profiles were designed to qualitatively approximate observations in the Amundsen Sea Embayment near Pine Island Glacier (Dutrieux et al., 2014). The COLD profile is at the surface freezing temperature at all depths and has a salinity such that the densities of the WARM and COLD profiles are nearly identical.

Table 5. Parameters for the COLD profiles.

\begin{tabular}{lll}
\hline Parameter & Value & Description \\
\hline$T_{0}$ & $-1.9^{\circ} \mathrm{C}$ & Surface temperature \\
$T_{\text {bot }}$ & $-1.9^{\circ} \mathrm{C}$ & Temperature at the ocean floor \\
$S_{0}$ & $33.8 \mathrm{PSU}$ & Surface salinity \\
$S_{\text {bot }}$ & $34.55 \mathrm{PSU}$ & Salinity at the ocean floor \\
\hline
\end{tabular}

For the ocean initial conditions and boundary forcing, linear profiles for potential temperature and salinity as functions of depth are given by

$$
\begin{aligned}
& T_{\text {res }}(z)=T_{0}+\left(T_{\text {bot }}-T_{0}\right) \frac{z}{z_{\mathrm{b}, \text { deep }}} \\
& S_{\text {res }}(z)=S_{0}+\left(S_{\text {bot }}-T_{0}\right) \frac{z}{z_{\mathrm{b}, \text { deep }}}
\end{aligned}
$$

where values at the surface $\left(T_{0}\right.$ and $\left.S_{0}\right)$ and at the ocean floor ( $T_{\text {bot }}$ and $S_{\text {bot }}$ ) correspond to either the COLD (Fig. 6 and Table 5) or WARM profiles (Fig. 6 and Table 6), depending on the experiment. The WARM profiles were chosen to produce strong thermal driving at depth but potential temperatures near freezing at the surface, qualitatively mimicking observations of deep, warm water observed in the Amundsen Sea region (Dutrieux et al., 2014). These relatively warm conditions, which result in large melt rates, are consistent with "warm" Antarctic ice shelves like those bordering the Amundsen and Bellingshausen Seas. The COLD profiles are consistent with ocean properties of "cold" Antarctic ice shelves like those bordering the Weddell and Ross Seas. The COLD potential temperature profile is constant at the surface freezing temperature throughout the water column and has a lower salinity, resulting in WARM and COLD density profiles that are nearly identical throughout the water column, thus reducing convective instabilities resulting from the transitions between COLD and WARM conditions that occur in Ocean1-2 as well as the MISOMIP1 IceOcean1-2 experiments.
Table 6. Parameters for the WARM profiles.

\begin{tabular}{lll}
\hline Parameter & Value & Description \\
\hline$T_{0}$ & $-1.9^{\circ} \mathrm{C}$ & Surface temperature \\
$T_{\text {bot }}$ & $1.0^{\circ} \mathrm{C}$ & Temperature at the ocean floor \\
$S_{0}$ & $33.8 \mathrm{PSU}$ & Surface salinity \\
$S_{\text {bot }}$ & $34.7 \mathrm{PSU}$ & Salinity at the ocean floor \\
\hline
\end{tabular}

\subsubsection{Boundary and initial conditions}

In the COM configuration, we request that participants use no-slip lateral boundary conditions at all walls including the northern wall adjacent to the restoring region and the calving front. We realize that free-slip or open boundary conditions may be more physically justifiable but no-slip boundary conditions are likely to be supported by the largest number of models. Also we prescribe no melting or drag from vertical ice faces (e.g., the calving front) both for simplicity and because many models do not support melting on vertical faces. Participants that use other boundary conditions should note this when they submit their results. The momentum boundary conditions at the ice-shelf base and seabed are quadratic drag with coefficients given in Table 4.

The ocean is initialized at rest with potential temperature and salinity profiles that are horizontally constant. The vertical functional forms of the initial profiles differ between the experiments, and are described below.

For TYP runs, no other model parameters or choices of model physics are prescribed. For COM runs, the recommended values for several relevant parameters are given in Table 4.

\subsubsection{COM grid resolution}

The nominal horizontal resolution for COM runs is $2 \mathrm{~km}$. We leave it at the discretion of modelers with horizontally unstructured grids to determine what a characteristic resolution of $2 \mathrm{~km}$ means for their model. 
Given the diversity of ocean-model vertical coordinates, it is not possible or useful to specify a vertical resolution that applies to all models. For this reason, we specify that all models should have 36 vertical layers, but we leave it at the modeler's discretion how the layers are distributed.

Many models will require a minimum ocean-column thickness. We recommend that models make the minimum ocean column as thin as can reasonably be achieved while retaining numerical stability and accuracy. For $z$ level models, the minimum thickness is likely to be approximately two grid cells $(\sim 40 \mathrm{~m}$ if $z$ levels are equally spaced). Models with other vertical coordinates may be less restricted, but some modification of the topography may be required to maintain a minimum ocean-column thickness. In locations where the ocean column is too thin, participants will need to decide for themselves whether it is more practical to modify the topography (ice draft, bathymetry or both) or to remove the column from the ocean (i.e., mark it as "land").

We recommend that $z$ level models use both partial top and bottom cells, if they are supported, for increased accuracy.

\subsubsection{COM mixing parameterizations}

Mixing is typically computed separately in the "horizontal" direction (i.e., within a model layer) and in the "vertical" direction (i.e., between model layers), regardless of which vertical coordinate is being used. To keep the experiments simple, we ask participants to perform "vertical" mixing with harmonic diffusion and the constant vertical viscosities and diffusivities given in Table 4. However, enhanced vertical mixing near the ice-ocean interface may be appropriate for models with high vertical resolution near the ice-ocean interface, since the buoyant sub-ice-shelf plume likely induces enhanced turbulent mixing that entrains ambient fluid. Models using non-constant vertical mixing should document the mixing scheme along with their results. Most models (e.g., those using the hydrostatic approximation) do not explicitly model convective instability. We prescribe a large vertical viscosity/diffusivity to be applied when the local stratification is unstable, with values given in the table. Participants whose models do not support this convective parameterization should note what other scheme was used to handle unstable stratification (e.g., convective adjustment or explicit modeling of convection).

"Horizontal" mixing should be parameterized with harmonic diffusion using a constant eddy viscosity/diffusivity. The values of the "horizontal" eddy viscosity and diffusivity have been chosen to be small but (hopefully) sufficient to damp grid-scale numerical noise at the COM resolution. Participants may need to increase these values for numerical stability, in which case this should be noted with their results (see Sect. 3.3). The vertical eddy viscosity and diffusivity have the same values as in the original ISOMIP experiment. We note that, in many models, it may be that numerical diffusion is larger than the explicit mixing.

\subsubsection{COM equation of state}

We prescribe a linear equation of state (EOS) with coefficients in Table 4:

$\rho=\rho_{\text {ref }}\left[1-\alpha_{\text {lin }}\left(T-T_{\text {ref }}\right)+\beta_{\text {lin }}\left(S-S_{\text {ref }}\right)\right]$.

For models that do not support a linear equation of state, we ask participants to note this and to describe the EOS they used in the pdf describing their model. Any model that requires $\rho_{\text {ref }}$ to be equal to $\rho_{\text {sw }}$ should use $\rho_{\text {ref }}$ for both values, and should note this difference along with their output.

\subsubsection{COM melt parameterization}

The recommended melt-rate formulation is the threeequation formulation with constant nondimensional heatand salt-transfer coefficients $\left(\Gamma_{\mathrm{T}}\right.$ and $\left.\Gamma_{\mathrm{S}}\right)$. Following Jenkins et al. (2010), Eqs. (1), (3), (4) and (5), we have

$\rho_{\mathrm{fw}} m_{\mathrm{w}} L=-\rho_{\mathrm{sw}} c_{\mathrm{w}} u_{*} \Gamma_{\mathrm{T}}\left(T_{z_{\mathrm{d}}}-T_{\mathrm{w}}\right)$,

$T_{z_{\mathrm{d}}}=\lambda_{1} S_{z_{\mathrm{d}}}+\lambda_{2}+\lambda_{3} p_{z_{\mathrm{d}}}$,

$\rho_{\mathrm{fw}} m_{\mathrm{w}} S_{z_{\mathrm{d}}}=-\rho_{\mathrm{sw}} u_{*} \Gamma_{\mathrm{S}}\left(S_{z_{\mathrm{d}}}-S_{\mathrm{w}}\right)$,

$u_{*}^{2}=C_{\mathrm{D}, \text { top }}\left(u_{\mathrm{w}}^{2}+u_{\text {tidal }}^{2}\right)$,

where $m_{\mathrm{w}}$ is the melt rate expressed in water equivalent $\left(w_{\text {eq }}\right), u_{*}$ is the friction velocity, $T_{z_{\mathrm{d}}}, S_{z_{\mathrm{d}}}$ and $p_{z_{\mathrm{d}}}$ are the potential temperature, salinity and pressure at the interface, and $u_{\mathrm{w}}, T_{\mathrm{w}}$ and $S_{\mathrm{w}}$ are the velocity magnitude, potential temperature and salinity some distance below the ice-shelf interface, as discussed below.

Because of differences in vertical resolution, vertical mixing and the method for computing $u_{\mathrm{w}}, T_{\mathrm{w}}$ and $S_{\mathrm{w}}$, appropriate values of the heat- and salt-transfer coefficients, $\Gamma_{\mathrm{T}}$ and $\Gamma_{\mathrm{S}}$, are likely to vary significantly between models. In Sect. 3.2.1, we prescribe a procedure for tuning these coefficients to achieve a desired mean melt rate. With the exception of $\Gamma_{\mathrm{T}}$ and $\Gamma_{\mathrm{S}}$, we prescribe values for the coefficients in Eqs. (24)-(27) in Table 4.

The liquidus coefficients in Eq. (25) are based on values from Jenkins et al. (2010) but have been modified to compute the potential freezing point. This should save modelers the trouble of converting the boundary-layer potential temperature to in situ temperature before computing the thermal driving. Modelers will need to determine the best method for computing the pressure at the ice-ocean interface, $p_{z_{\mathrm{b}}}$, as we do not prescribe a method for doing so here. One commonly used method (Losch, 2008) computes $p_{z_{\mathrm{b}}}$ by integrating a reference density profile from sea level to the ice draft.

For simplicity, the ice is considered to be perfectly insulating. This means that modelers should not use the advectiondiffusion scheme from Holland and Jenkins (1999) to determine the heat flux into the ice shelf, as is common practice in ice-shelf cavity modeling. Top and bottom friction are computed with a quadratic drag law (surface stresses are proportional to the square of the local ocean flow speed) using drag 
coefficients from Hunter (2006), as given in the table. The root-mean-square "tidal" velocity, $u_{\text {tidal }}$, is used to parameterize the turbulent mixing that would be induced by tides if they were present and is used to prevent the friction velocity (and thus the melt rate) from going to zero when there is no motion under the ice shelf. The computation of top and bottom drag do not incorporate $u_{\text {tidal }}$.

Methods for computing the "far-field" potential temperature, salinity and velocity $\left(T_{\mathrm{w}}, S_{\mathrm{w}}\right.$ and $\left.u_{\mathrm{w}}\right)$ differ across models. Some models sample these fields at a fixed distance below the ice draft (e.g., Kimura et al., 2013) while others average the fields over a prescribed thickness (e.g., Losch, 2008). Participants are asked to describe how $T_{\mathrm{w}}, S_{\mathrm{w}}$ and $u_{\mathrm{w}}$ are computed in the pdf included with their results.

Some models will use virtual salt fluxes, while others will use volume fluxes (or perhaps mass fluxes) at the ice-ocean boundary. The freshwater, heat and salt fluxes for models using virtual salt fluxes should be computed following Jenkins et al. (2001) as

$$
\begin{aligned}
& F_{\mathrm{fw}}=0, \\
& F_{\mathrm{H}}=-c_{\mathrm{w}}\left(\rho_{\mathrm{sw}} u_{*} \Gamma_{\mathrm{T}}+\rho_{\mathrm{fw}} m_{\mathrm{w}}\right)\left(T_{z_{\mathrm{d}}}-T_{\mathrm{w}}\right), \\
& F_{\mathrm{S}}=-\left(\rho_{\mathrm{sw}} u_{*} \Gamma_{\mathrm{S}}+\rho_{\mathrm{fw}} m_{\mathrm{w}}\right)\left(S_{z_{\mathrm{d}}}-S_{\mathrm{w}}\right) .
\end{aligned}
$$

If volume fluxes are used instead, the same fluxes are given by

$$
\begin{aligned}
& F_{\mathrm{fw}}=\rho_{\mathrm{fw}} m_{\mathrm{w}}, \\
& F_{\mathrm{H}}=-c_{\mathrm{w}}\left[\rho_{\mathrm{fw}} m_{\mathrm{w}} T_{z_{\mathrm{b}}}+\rho_{\mathrm{sw}} u_{*} \Gamma_{\mathrm{T}}\left(T_{z_{\mathrm{d}}}-T_{\mathrm{w}}\right)\right], \\
& F_{\mathrm{S}}=0 .
\end{aligned}
$$

Though we do not require it, models may wish to distribute melt fluxes over several vertical grid cells, as in Losch (2008). This approach parameterizes additional vertical mixing within the boundary layer and may prevent noise and/or time-step restrictions in models with very thin cells below the ice-ocean interface. This is an alternative approach to representing the enhanced turbulent mixing near the ice-ocean interface mentioned in Sect. 3.1.6.

Models using volume or mass fluxes will need a strategy for removing mass in the open ocean to compensate for the volume of meltwater that enters the domain. Because of the small size of the domain, without such a strategy, sea level would likely rise by hundreds of meters in simulations with large melt rates (Ocean1 and Ocean3). One possible approach is to impose an artificial evaporative flux in the restoring region $(x>790 \mathrm{~km})$. Corresponding salt and heat fluxes will be needed to prevent the top cells from becoming cooler and saltier as mass leaves the cell:

$$
F_{\mathrm{e}}=-\rho_{\mathrm{sw}}\left\langle m_{\mathrm{w}}\right\rangle \frac{A_{\text {shelf }}}{A_{\text {res }}},
$$

$F_{\mathrm{H}, \mathrm{e}}=c_{\mathrm{w}} T_{0} F_{\mathrm{e}}$,

$F_{\mathrm{S}, \mathrm{e}}=S_{0} F_{\mathrm{e}}$,

where $F_{\mathrm{e}}, F_{\mathrm{H}, \mathrm{e}}$ and $F_{\mathrm{S}, \mathrm{e}}$ are the evaporative mass, heat and salt flux, respectively, $A_{\text {res }}$ is the area of the restoring region, $T_{0}$ and $S_{0}$ are the prescribed temperature and salinity at the ocean surface in the restoring profile, and $\left\langle m_{\mathrm{w}}\right\rangle$ is the melt rate averaged over the area of the ice shelf $A_{\text {shelf }}$ and over a suitable period of time (perhaps 1 month). Participants are welcome to use alternative strategies. They are asked to document whichever approach (if any) they use for removing excess mass in their description pdf.

\subsection{Experiments}

Ocean0-2 involve static ice-shelf topography, making them accessible to a wider range of ocean models. They are intended to represent the most advanced and most retreated states in the coupled ice sheet-ocean system to come later. These experiments are designed to test how changes in farfield ocean forcing result in changes in melt rates, which would drive ice-sheet dynamics in the coupled system. Preliminary simulations with POP2x suggest that, in each experiment, the system will experience an initial shock lasting a few days as the ocean water in contact with the ice shelf adjusts to the melting/freezing boundary conditions. In Ocean 0 , strong melting begins immediately, and the system reaches a quasi-equilibrium within a few months. In Ocean1 and Ocean2, far-field changes in ocean properties take several years to propagate into the ice-shelf cavity, leading to a substantial increase (in Ocean1) or decrease (in Ocean2) in melting.

Ocean 3 and Ocean 4 make use of dynamic ice topography that evolves over 100 years. Whereas preliminary results suggest that Ocean0-2 approach or have reached quasiequilibria by the end of each experiment, Ocean3-4 do not reach steady state because of the evolving topography.

Figure 7 shows time series of area-averaged melt rate for four of the five ISOMIP+ experiments from example POP2x simulations. Melt rates from Ocean0, not shown, are nearly indistinguishable from the first year of the Ocean 3 experiment.

In the following sections, we present further results from these POP2x simulations. In each case, we show the evolution of a transect through the ocean temperature field through the center of the domain, which also indicates how the ice topography evolves (if at all) over time. We emphasize that we do not intend these results to be treated as a benchmark for other participants to try to match. Instead, the examples show that the simulations can be performed and that they achieve their intended purposes. They should give the participants a qualitative idea of what to expect. After all, the MIP is not to attempt to produce identical results with all models but rather to try to understand the differences that occur. 


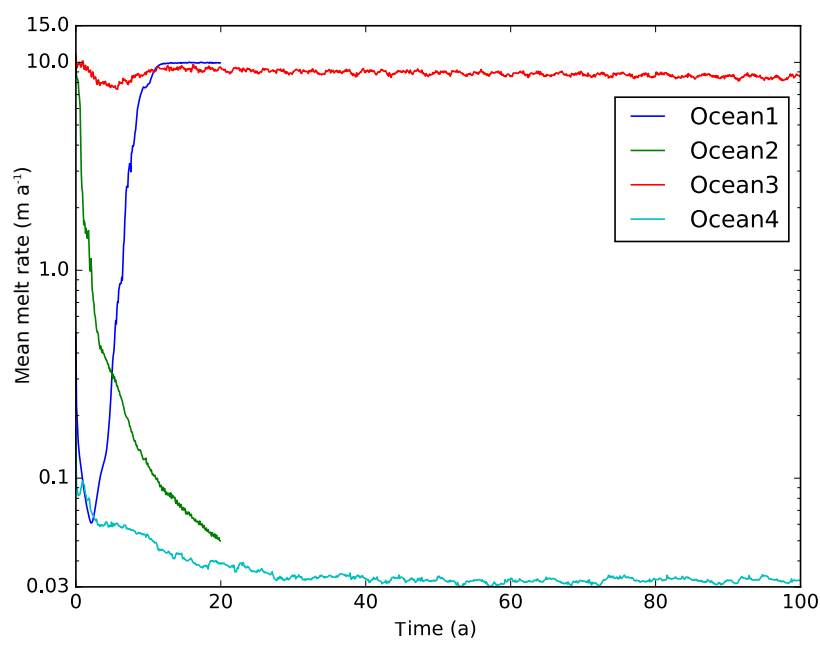

Figure 7. Example results from POP2x simulations showing melt rates averaged over the shelf area as functions of time for Ocean1-4. Melting increases by nearly 2 orders of magnitude in Ocean 1 , and decreases by about the same order in Ocean2, demonstrating that changes in far-field forcing can greatly increase or reduce melting. After a decade or two of initial adjustment, the melt rates in Ocean3 and Ocean4 remain relatively steady in time despite the changing topography in those experiments, suggesting that the total cavity size has relatively little impact on total melting.

\subsubsection{Ocean0: warm initial conditions and forcing with static ice-shelf topography}

Ocean0 uses steady-state ice topography, as shown in the transects in Fig. 8, from the initial steady state of the MISMIP+ Ice1 experiment (see Sect. 2.2) produced with BISICLES using the SSA and no melting. The ocean is initialized with the WARM profiles in Fig. 6 and restored the same profile in the far field.

The combination of warm initial conditions and restoring is expected to lead the system to reach a quasi-equilibrium with strong melting over a few months to a year, based on preliminary results. The duration of the run should be the time needed to reach a quasi-equilibrium melt rate plus 6 months, so that time averages without trends may be taken over the final 6 months of the simulation. We expect the total run duration to be between 1 and 2 years.

Because Ocean0 is expected to reach a quasi-equilibrium within approximately 1 year, this experiment is well suited to parameter studies. In particular, we use this experiment to calibrate the values of the heat- and salt-transfer coefficients, $\Gamma_{\mathrm{T}}$ and $\Gamma_{\mathrm{S}}$ to achieve a target melt rate:

$\left\langle m_{\mathrm{w}}\right\rangle=30 \pm 2 \mathrm{ma}^{-1}$,

where the brackets indicate the average of $m_{\mathrm{w}}$ over the area where $z_{\mathrm{b}}<-300 \mathrm{~m}$ and over the final 6 months of the simulation. We focus on the melt rate over the deeper portion of the ice draft because we expect larger (therefore more dynamically relevant) melt rates in this region. Participants should use an optimization approach such as sampling or a continuation method to find a value of $\Gamma_{\mathrm{T}}$ such that $\left\langle m_{\mathrm{w}}\right\rangle$ lies within the prescribed bounds. At each stage, the value of $\Gamma_{\mathrm{S}}$ should also be modified such that $\Gamma_{\mathrm{S}}=\Gamma_{\mathrm{T}} / 35$ (McPhee et al., 2008; Jenkins et al., 2010). Fits to observations suggest that the thermal Stanton number is on the order of $S t=$ $\sqrt{C_{\mathrm{D} \text {,top }}} \Gamma_{\mathrm{T}}=1.1 \times 10^{-3}$ (Jenkins et al., 2010), suggesting that $\Gamma_{\mathrm{T}}=2.2 \times 10^{-2}$ might be a good initial guess. Figure 9 shows an example of the tuning process applied in POP2x, plotting $\left\langle m_{\mathrm{w}}\right\rangle$ for various values of $\Gamma_{\mathrm{T}}$. The melt rate is $\sim 30$ $\mathrm{ma}^{-1}$ when $\Gamma_{\mathrm{T}} \approx 0.11$ for this model. Figure 8 shows example Ocean0 results from POP $2 x$ with $\Gamma_{\mathrm{T}} \approx 0.115$.

Models with high resolution near the ice-ocean interface may wish to deviate from the prescribed value of $C_{\mathrm{D} \text {,top }}$ in addition to tuning $\Gamma_{\mathrm{T}}$ and $\Gamma_{\mathrm{S}}$. For example, at high vertical resolution (higher than 0.1-1 m), the log law of the wall, in which $C_{\mathrm{D}}$ is a function of the $\log$ of the distance from the interface, is used in some models (Oey, 2006). Participants that use a value or functional form for $C_{\mathrm{D} \text {,top }}$ other than that given in Table 4 should document this with their submitted results.

\subsubsection{Ocean1: cold initial conditions and warm forcing with static ice-shelf topography}

Ocean 1 uses the same topography and restoring as Ocean 0 but is initialized to a colder, fresher profile (COLD from Fig. 6) that is expected to result in low melt rates during the first several years of the simulation. Far-field restoring to the WARM profiles leads to warmer and saltier water in the far field at depth.

It is worth noting that this COLD-to-WARM scenario represents a transition between the two extremes of water masses observed on the Antarctic continental shelf, and is therefore an unrealistic scenario designed to test the response of models to an extreme forcing.

The duration of the experiment is exactly 20 years (from the beginning of the date 1 January 0000 to the end of 31 December 0019), which preliminary results suggest is sufficient time to reach a quasi-steady state. Melt rates as well as the strengths of the barotropic and overturning circulations toward the end of the simulation are expected to be significantly larger than those within the first few years because of the warming.

Example results from a POP2x Ocean1 simulation, the top row of Fig. 10, show that warm water at depth gradually advects and mixes into the cavity during the first decade, becoming quasi-steady over the second decade. Melt rates from Fig. 7 are initially low, corresponding to a relatively weak overturning circulation. This weak circulation means that warm, deep water is pulled into the cavity only gradually over most of the first decade. As warmer water reaches the back of the cavity, melt rates increase, driving stronger overturning and drawing more warm water. This positive feed- 

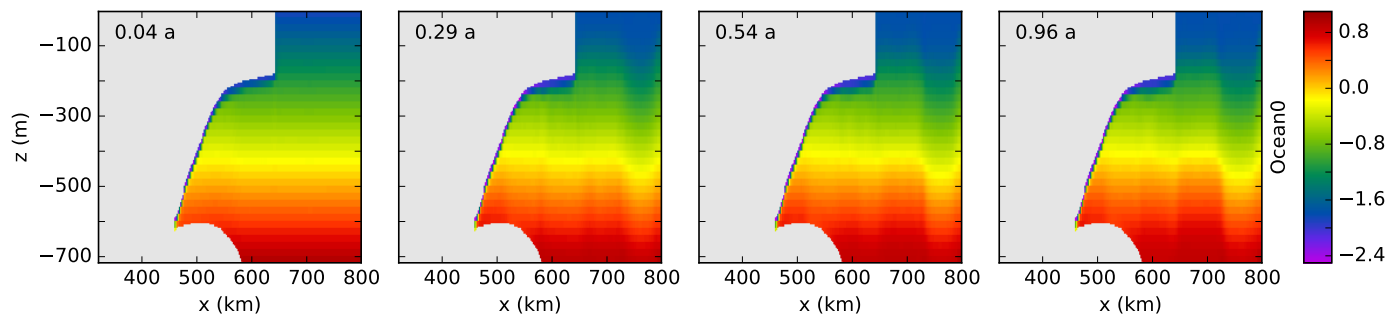

Figure 8. Example results from a 1-year Ocean0 simulation with the POP $2 x$ model using heat-transfer coefficient $\Gamma_{\mathrm{T}}=0.11$. Panels show the progression in time of transects of monthly averaged ocean temperature through the center of the domain $(y=40 \mathrm{~km})$. The initial conditions and far-field restoring at the right-hand side of the domain both use the WARM profiles from Fig. 6 . The ice draft does not evolve in time. The simulation reaches a quasi-steady state with relatively strong melting within a few months.

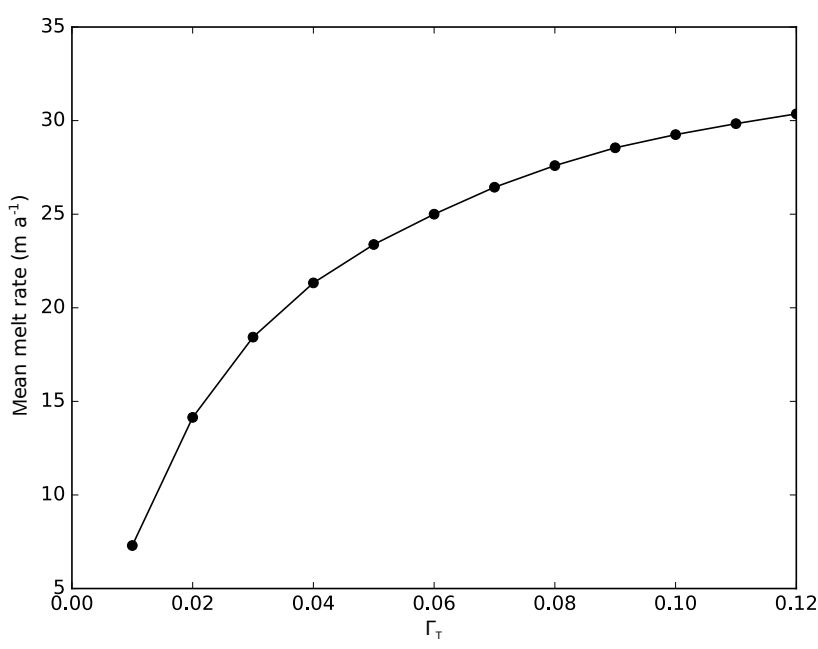

Figure 9. Example results from a series of POP2x simulations of Ocean0 showing the dependence of the mean melt rate $\left\langle m_{\mathrm{W}}\right\rangle$ averaged over locations below $z_{\mathrm{d}}=-300 \mathrm{~m}$ and over the final 6 months of the simulation for various values of the turbulent heat-transfer coefficient $\Gamma_{\mathrm{T}}$. Based on these results, the value $\Gamma_{\mathrm{T}} \approx 0.11$, corresponding to a mean melt rate $m_{\mathrm{W}} \approx 30 \mathrm{ma}^{-1}$, was used for subsequent ISOMIP+ and MISOMIP1 simulations.

back saturates over the coarse of several years once melt rates have increased by several orders of magnitude. The system remains in quasi-steady state for approximately the second half of the experiment.

\subsubsection{Ocean2: warm initial conditions and cold forcing with static ice-shelf topography}

In Ocean2, the topography is from the end of Ice1r (see Sect. 2.2) using BISICLES with the SSA. A temperature transect through the center of the domain can be seen in each panel of the bottom row of Fig. 10. The ocean is initialized with the WARM profiles and restored to the COLD profiles in Fig. 6, with parameters given in Tables 5 and 6. Again, the experiment should run for 20 years. As in Ocean1, the abrupt change between forcing profiles is unrealistically strong and is designed to test how the participating models respond to extreme changes.

The bottom row of Fig. 10 and the green curve in Fig. 7 show example POP2x results from Ocean2. Initially, strong circulation driven by warm ocean temperatures and rapid melting pull in cold water from the far field. As this cold water reaches the back of the cavity within the first year, the melt rate begins to fall, decreasing by several orders of magnitude over the course of the simulation. The slower overturning during much of the simulation means that the timescale required to reach a quasi-steady state is longer for Ocean 2 than for Ocean1 and equilibrium has not been reached after 20 years.

\subsubsection{Ocean3: warm initial conditions and forcing with retreating ice-shelf topography}

Ocean 3 begins with the same topography as Ocean 1 , but in this experiment the ice draft evolves over time according to a prescribed data set covering 100 years of ice retreat from Ice1r. Ocean3 is initialized and forced with the WARM profile. We expect strong melting to begin immediately as the sub-ice-shelf circulation spins up, consistent with the conditions for Ice1r used to generate the topography, and to persist for the duration of the experiment.

The topography for Ocean3, available through Cornford and Asay-Davis (2016), includes snapshots of the ice draft and ice surface at yearly intervals on a $1 \mathrm{~km}$ grid. We expect that the frequency with which ocean models can update their topography may vary considerably, from once per time step in some models to monthly or yearly in others. Participants wishing to update more frequently than yearly should interpolate the ice draft linearly between subsequent geometries to determine the topography at intermediate times. As previously mentioned, we have not applied the calving criteria to the topography provided because calving should be applied only after interpolation in time and space. This means that models that update the topography only every year and thus require no interpolation in time will need to apply the calving criteria themselves. 

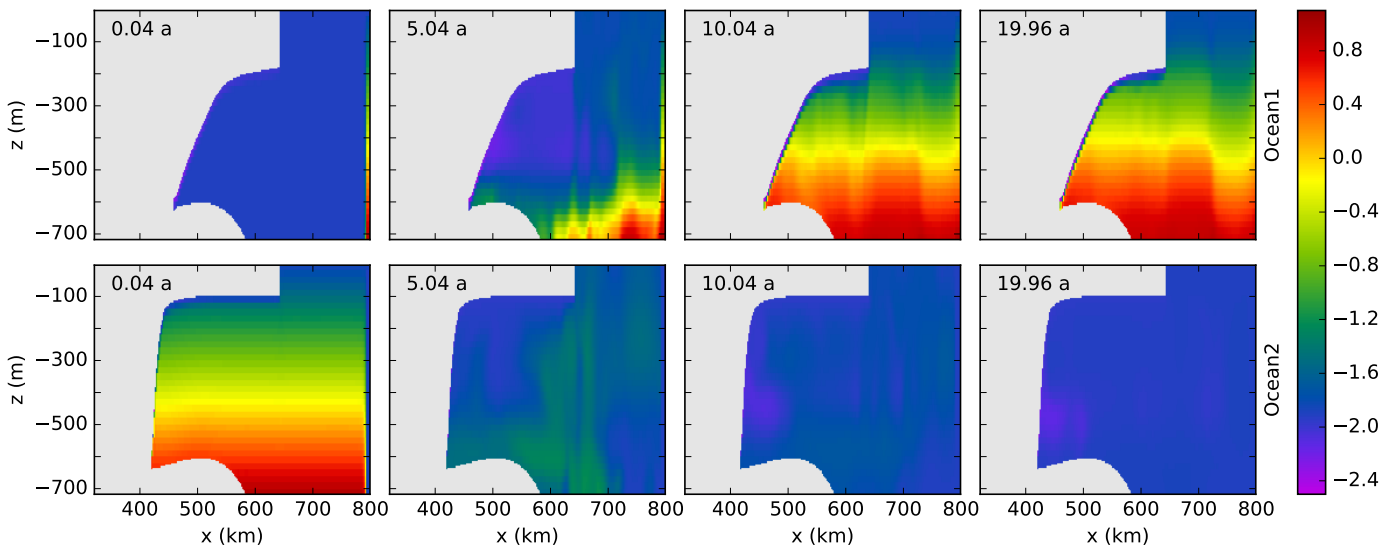

Figure 10. Example results from POP2x as in Fig. 8 but for Ocean1 (top) and Ocean2 (bottom) simulations each lasting 20 years. In both experiments, the ice draft is held fixed in time. Ocean1 is initialized with COLD profiles and restored to WARM profiles. Melt rates are initially low and the overturning strength is initially relatively weak, so that warm, deep water takes several years to reach the back of the sub-ice-shelf cavity, at which point melting increases by several orders of magnitude, reaching a quasi-steady state for approximately the second half of the experiment. Ocean2 is initialized with WARM profiles and restored to COLD profiles, leading to a melt rate that decays by several orders of magnitude over the duration of the simulation. Ocean 2 does not reach a quasi-steady state within its 20 -year duration.

The red curve in Fig. 7 shows melt rates from Ocean3, and the top row of Fig. 11 shows a transect of monthly-averaged temperature as well as the evolving ice topography at four points in time. Mean melt rates remain strong throughout the simulation. As the ice draft steepens, melting becomes concentrated near the grounding line within the trough. As the cavity grows, melt fluxes remain strong but the mean melt rate decreases somewhat because of the increased area.

\subsubsection{Ocean4: cold initial conditions and forcing with advancing ice-shelf topography}

Conceptually, Ocean4 is an extension of Ocean3. The icedraft topography from Ice1ra was produced by abruptly shutting off melting at year 100 and allowing the ice to readvance for 100 years (see Sect. 2.2). Thus, Ocean4 begins with the final topography from Ocean 3 (which is also the same topography as in Ocean2). This time, we prescribe both initialization and restoring to the COLD salinity and potential temperature profile, which should lead to very low melt rates, consistent with the lack of melting in the MISMIP+ run that produced the ice topography. As in Ocean3, yearly topography data at $1 \mathrm{~km}$ resolution are provided through Cornford and Asay-Davis (2016). Once again, participants will need to apply the calving criteria to these data.

Example results from POP2x show that melt rates remain low for the duration of the simulation (cyan curve in Fig. 7) and that temperatures in the cavity evolve toward the freezing point over the first several decades, reaching a quasi-steady state after $\sim 30$ years. A transect through the temperature field in the bottom row of Fig. 11 also shows the evolving ice topography.

\subsection{Requested output}

Participants are asked to supply a number of fields interpolated to a standard grid. NetCDF files with example output on the standard grid are available for download (see Sect. 6). Participants are asked to supply a single NetCDF4 file for each experiment with the file-naming convention of [expt]_COM_[MODEL].nc, where [expt] is an experiment name from Table 2, COM or TYP indicates the type of run and $[M O D E L]$ is a unique identifier for the participant (e.g., the name of the ocean model and/or the institute). We ask participants to provide all fields in 32-bit floating-point precision using the variable and dimension names given in bold and units given in square brackets as follows.

- nx, ny, nz and nTime dimensions.

- $\mathbf{x}(\mathrm{nx}),[\mathrm{m}]$ vector of cell centers in the $x$ direction on the output grid with 2 -km spacing, $3.21 \times 10^{5}, 3.23 \times 10^{5}$, ... $7.99 \times 10^{5}$.

- $\mathbf{y}(\mathrm{ny}),[\mathrm{m}]$ vector of cell centers in the $y$ direction on the output grid with 2 -km spacing, $1.0 \times 10^{3}, 3.0 \times 10^{3}, \ldots$ $7.9 \times 10^{4}$.

- $\mathbf{z}(\mathrm{nz}),[\mathrm{m}]$ vector of cell centers in the $z$ direction on the output grid with $5-\mathrm{m}$ spacing, $-2.5,-7.5 \ldots-717.5$.

- time(nTime) [s] from the start of the simulation as a vector running over the full duration of the simulation (20 years for Ocean1 and Ocean2, 100 years for Ocean3 and Ocean4). The time interval between entries is 1 month, using a standard 365 day calendar with no leap years. 

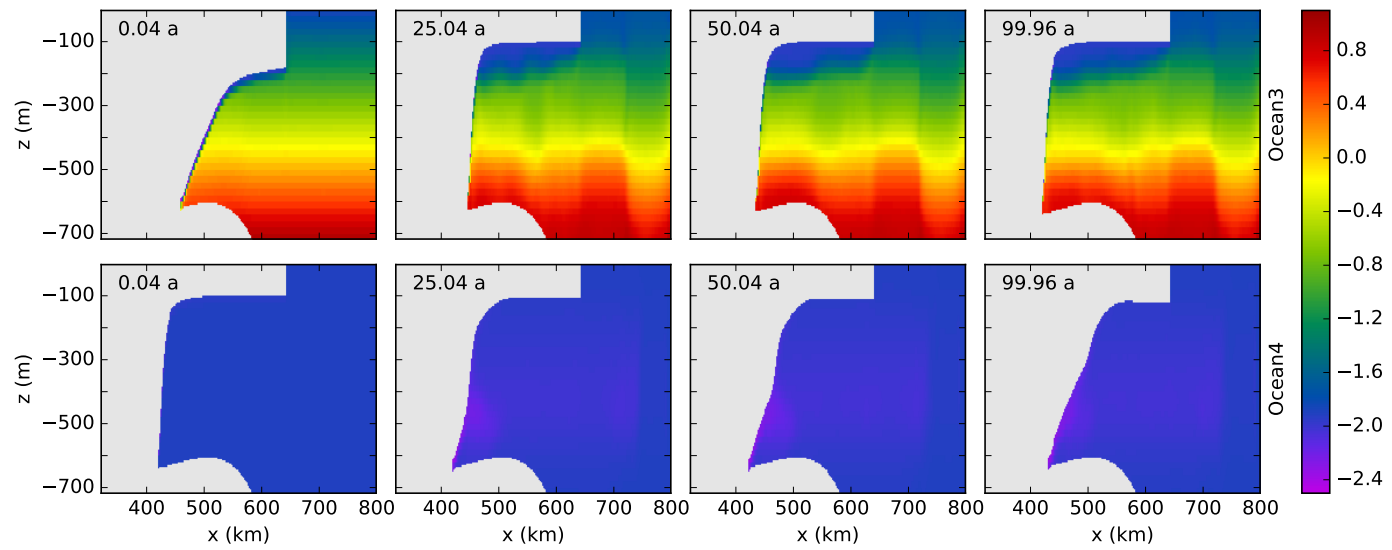

Figure 11. Example results from POP2x as in Fig. 8 but for Ocean3 (top) and Ocean4 (bottom) simulations each lasting 100 years. In these experiments, the ice draft evolves in time. Ocean3 prescribes WARM initial conditions and restoring, producing strong melting throughout the experiment, consistent with the retreating ice. The melt rate declines slightly over the course of the simulation as the ice retreats to shallower depths, associated with colder ocean temperatures. Ocean4 is initialized and forced with COLD profiles, which lead to relatively low melt rates, fitting with the advancing ice topography. Meltwater cools the sub-shelf cavity, leading to several decades of decreasing melt rates followed by quasi-steady values for the remainder of the simulation.

- meanMeltRate(nTime) $\left[\mathrm{m} \mathrm{s}^{-1}\right] w_{\text {eq }}$, the melt rate, positive for melting and negative for freezing, averaged over the ice-shelf base.

- totalMeltFlux(nTime) $\left[\mathrm{kg} \mathrm{s}^{-1}\right]$, the total mass flux of freshwater across the ice-ocean interface, positive for melting and negative for freezing.

- totalOceanVolume(nTime) $\left[\mathrm{m}^{3}\right]$, the total volume of the ocean.

- meanTemperature $(\mathrm{nTime})\left[{ }^{\circ} \mathrm{C}\right]$, the potential temperature averaged over the ocean volume.

- meanSalinity(nTime) [PSU], the salinity averaged over the ocean volume.

- iceDraft(nTime,ny,nx) [m], the elevation of the iceocean interface $\left(z_{\mathrm{d}}\right)$. Dependence on time is only needed for Ocean 3 and Ocean4.

- bathymetry(nTime,ny,nx) [m], the elevation of the bathymetry $\left(z_{\mathrm{b}}\right)$. Dependence on time is only needed for Ocean3 and Ocean4.

- meltRate(nTime,ny,nx) $\left[\mathrm{m} \mathrm{s}^{-1}\right] w_{\mathrm{eq}}$, the melt rate, positive for melting and negative for freezing.

- frictionVelocity(nTime,ny,nx) $\left[\mathrm{m} \mathrm{s}^{-1}\right]$, the friction velocity $u_{*}$ used in melt calculations.

- thermalDriving(nTime,ny,nx) $\left[{ }^{\circ} \mathrm{C}\right]$, the thermal driving used in the melt calculation. The thermal driving is the difference between the potential temperature in the boundary layer, $T_{\mathrm{w}}$, and the freezing potential temperature at the ice-ocean interface, $T_{z_{\mathrm{d}}}$.
- halineDriving(nTime,ny,nx) [PSU], the haline driving used in the melt calculation. The haline driving is the difference between the salinity in the boundary layer, $S_{\mathrm{w}}$ and the salinity at the ice-ocean interface, $S_{z_{\mathrm{d}}}$.

- uBoundaryLayer(nTime,ny,nx) and vBoundaryLayer(time, y, x) $\left[\mathrm{ms}^{-1}\right]$, the components of the velocity in the boundary layer that were used to compute $u_{*}$.

- barotropicStreamfunction(nTime,ny,nx) $\left[\mathrm{m}^{3} \mathrm{~s}^{-1}\right]$, the barotropic streamfunction, $\psi_{x y}$, such that the barotorpic velocity, $\mathbf{U}$, is $\left(U=-\partial \psi_{x y} / \partial y, V=\partial \psi_{x y} / \partial x\right)$.

- overturningStreamfunction(nTime,nz,nx) $\quad\left[\mathrm{m}^{3} \mathrm{~s}^{-1}\right]$, the overturning streamfunction, $\psi_{x z}$, in $x-z$ such that the zonal-mean velocity, $\overline{\mathbf{u}}$, is $\left(\bar{u}=-\partial \psi_{x z} / \partial z\right.$, $\left.\bar{w}=\partial \psi_{x z} / \partial x\right)$.

- bottomTemperature(nTime,ny,nx) $\quad\left[{ }^{\circ} \mathrm{C}\right] \quad$ and bottomSalinity(nTime,ny,nx) [PSU], the potential temperature and salinity in the bottom-most cell in each ocean column.

- temperatureXZ(nTime,nz,nx) $\left[{ }^{\circ} \mathrm{C}\right] \quad$ and salinityXZ(nTime,nz,nx) [PSU], the potential temperature and salinity transects in $x-z$ plane through the center of the domain, $y=40 \mathrm{~km}$.

- temperatureYZ(nTime,nz,ny) $\quad\left[{ }^{\circ} \mathrm{C}\right] \quad$ and salinityYZ(nTime,nz,ny) [PSU], the potential temperature and salinity transects in $y-z$ plane outside the cavity $x=520 \mathrm{~km}$.

Invalid values (e.g., field locations that lie within the ice shelf or bedrock) should be masked out using a fill value. In $\mathrm{C}$ and 
Fortran, this can be accomplished by assigning a value of NC_FILL_FLOAT and setting the _FillValue attribute of the NetCDF variable to this value. In Python, invalid data can be masked by using numpy masked arrays to assign to netCDF4 variables.

We ask participants to supply monthly mean values of all time-dependent quantities (except iceDraft and bathymetry, which should be snapshots), where the values in the time array indicate the beginning of the period being averaged. Participants who are unable to compute monthly mean values may supply snapshots instead but should indicate this with their submission.

We note that many functions are typically computed on staggered grids. For example, the barotropic streamfunction is typically computed at horizontal cell corners (vertices) and the overturning streamfunction is typically computed at cell corners on the vertical grid. Velocity components (uBoundaryLayer and vBoundaryLayer) are typically located at cell edges (on a C-grid) or cell corners (on a B-grid). Additionally, for most models, potential temperature and salinity fields will not have values exactly at $y=40 \mathrm{~km}$ as requested in temperatureXZ and salinity XZ (and similarly for the $y-z$ transects). To aid in analysis and comparison of results, we ask all participants to interpolate these fields to the standard grid. The standard grid has a high vertical resolution $(\Delta z=5 \mathrm{~m})$ in an attempt to accommodate models with a variety of vertical coordinates. Participants are welcome to provide plots of their results on their model's native grid in addition to supplying the output on the standard grid.

Participants are asked to provide the iceDraft and bathymetry, which are time dependent for Ocean 3 and Ocean4, to show how topography has been modified (interpolated in time, smoothed, the ocean column thickened, etc.).

Two python scripts for plotting the contents of a properly formatted results file are available in the Supplement (plotMISOMIPOceanData.py and plotMisomipoceanMetrics.py). Plots of the example POP2x simulation results produced with this script are available for download (see Sect. 6).

We ask participants to include a description of the result in a pdf file (using the same naming convention as the results, i.e., [expt]_COM_[MODEL] .pdf) describing several specific properties of their model and its ISOMIP+ configuration. If appropriate, a single pdf can be used to describe Ocean 1-4 results, as has been done in the example included in the Supplement. These include

1. model: the name and version of the model used (as specifically as possible, including a citation if available);

2. repository: a link to the repository where the model can be downloaded (if public) and specific tag, branch or revision (if available);
3. vertical coordinate: description of the vertical coordinate of the model ( $z$ level, $z^{*}$, terrain, isopycnal, etc.);

4. horizontal mixing: description of how "horizontal" mixing was performed (harmonic, biharmonic, etc.; within model levels, along geopotentials, along isopycnals, etc.);

5. vertical mixing: description of how "vertical" mixing was performed (constant diffusivity, $k$ profile parameterization, etc.; harmonic, biharmonic, etc.);

6. advection: description of the momentum- and traceradvection schemes used (centered, third-order with limiter, etc.);

7. EOS: description of the equation of state;

8. convection: description of the procedure for handling convection (explicitly modeled, parameterized using strong vertical mixing, etc.);

9. melt parameterization: description of how $T_{\mathrm{w}}, S_{\mathrm{w}}$ and $u_{\mathrm{w}}$ in the melt parameterization are computed from $T$, $S$ and $\boldsymbol{u}$ fields (e.g., averaging over the boundary layer, sampling at a fixed distance);

10. topography: description of procedure for interpolating, smoothing or otherwise modifying the ice draft and/or bedrock topography;

11. maintaining sea level: description of strategy (if any) for maintaining sea level when volume or mass fluxes are used (e.g., use of Eq. 34);

12. moving boundaries: for Ocean 3 and Ocean 4 , a description of how the moving boundary is implemented (e.g., how $T, S$ and $\boldsymbol{u}$ are computed in cells or ocean columns that were previously ice-filled and redistributed, if at all, when a cell or column is filled with ice);

13. TYP parameters: for TYP results, details on resolution as well as melt and mixing parameterizations;

14. TYP problem: for TYP results, a description of the types of problems the participant would typically apply the model to using this configuration (e.g., which region; over what time span; with what kind of initialization, forcing and boundary conditions);

15. COM deviations: for COM results, details anywhere the model deviated from the COM resolution or the COM melt and mixing parameterizations;

16. COM parameters: for COM results, the values of $\Gamma_{\mathrm{T}}$ and $\Gamma_{\mathrm{S}}$. Also, the value of $C_{\mathrm{D} \text {,top }}$ if different from the prescribed value; 
17. $\Gamma_{\mathrm{T}}$ figure: for COM Ocean0 results, a figure similar to Fig. 9 showing how the melt rate for $z_{\mathrm{d}}<-300 \mathrm{~m}$ varies with $\Gamma_{\mathrm{T}}$.

We provide an example in the Supplement.

\section{MISOMIP1 design}

MISOMIP1 prescribes two coupled ice sheet-ocean experiments (IceOcean1-2, summarized in Table 2), each with two parts. We expect the MISOMIP1 experiment to play an analogous role in evaluating coupled ice sheet-ocean systems to that of the ISOMIP projects for stand-alone ocean models with ice-shelf cavities and the MISMIP projects for ice-sheet models. We ask participants to first perform the MISMIP+ and ISOMIP+ experiments, so that the behavior of each component on its own has been documented, before proceeding to MISOMIP1.

For both MISOMIP1 experiments, the bedrock topography is the same as for MISMIP+ and ISOMIP+, as given by Eqs. (1)-(4). Ice-sheet parameters are the same as for MISMIP+ except where noted below. To simplify the coupled problem, we prescribe a constant ice temperature as in MISMIP+ and set the thermal conductivity of ice to zero (so that there is no sensible heat flux into ice at the iceocean interface). Thus, the only flux across the ice-ocean interface is of meltwater. As in ISOMIP+, freshwater fluxes come only from melting. Calved ice disappears abruptly (or as abruptly as the ocean component can handle, since some ocean models will need a finite period of adjustment to prevent tsunamis) without producing a freshwater flux into the ocean.

\subsection{IceOcean1: retreat and re-advance without dynamic calving}

IceOcean 1 begins with the ice-sheet steady state that also served as the initial conditions for the MISMIP+ Ice0, Ice1 and Ice2 experiments (see Sect. 2.2). Unlike in ISOMIP+, IceOcean 1 does not include a dynamic calving criterion. Ice is allowed to become as thin as the ice sheet and ocean components permit (potentially zero thickness) without calving. As in MISMIP + and ISOMIP + , ice beyond $x=640 \mathrm{~km}$ is considered to have calved.

The experiment consists of two phases - a 100-year retreat phase, IceOcean1r, and a 100-year re-advance phase, IceOcean1ra. At the beginning of IceOcean1r, the ocean component is initialized with the steady-state ice topography from the ice-sheet component and the COLD salinity and temperature profiles from Fig. 6 and Table 5. The initial state should be cold enough to produce low melt rates $\left(\sim 0.2 \mathrm{~m} \mathrm{a}^{-1}\right.$ in preliminary tests) that are approximately consistent with the ice sheet's initial state. For the 100-year duration of IceOcean1r, restoring to the WARM profile (see Fig. 6 and Table 6) is applied near the ocean's northern boundary. As in ISOMIP+
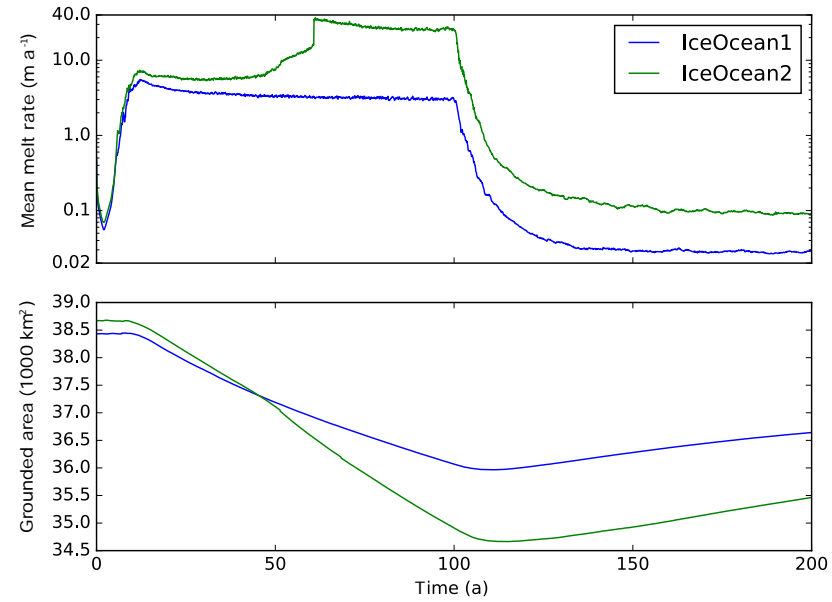

Figure 12. Example results from POPSICLES simulations of IceOcean1 (no dynamic calving) and IceOcean2 (thickness-based calving criterion) using SSA and the sliding law from Weertman (1974) showing melt rates averaged over the shelf area (top panel) and the grounded area as functions of time (bottom panel). Though melt rates are initially similar, after about year 40 the dynamic calving in IceOcean 2 begins to remove substantial areas of the ice shelf (notably when an iceberg is removed just after year 60), resulting in larger mean melt rates (but similar total melt fluxes) for that experiment. IceOcean 2 loses substantially more grounded area than IceOcean1 during retreat (the first 100 years), presumably due to a loss of buttressing from the ice shelf, which has nearly completely calved away. The grounding line re-advances at approximately the same rate in both experiments because the advancing shelf it thick enough not to calve.

Ocean1, the warm water is expected to reach the ice-shelf cavity within the first decade, at which point it should induce strong melting and subsequent rapid ice retreat.

The re-advance phase, IceOcean1ra, begins where IceOcean $1 \mathrm{r}$ ends but abruptly switches to the COLD restoring profile at the ocean's northern boundary. The simulation evolves for another 100 years, during the first decade of which the ocean should cool and the melt rate should be greatly reduced, similarly to Ocean 2 . The reduced melting should allow ice to re-advance for the remainder of the simulation.

The blue curves in Fig. 12 shows the mean melt rate and the grounded area and from an IceOcean1 simulation using the POPSICLES model (coupled POP2x and BISICLES). The top row of Fig. 13 shows the evolution of the ice draft and ocean temperature over the course of the simulation. The mean melt rate is initially relatively small, increasing by several orders of magnitude over the first decade as warm water reaches the cavity and initiating grounding-line retreat. Because of the ocean temperature profile, the melt rate is a strong function of the depth of the ice-ocean interface. As the ice shelf thins, melting becomes concentrated over a steep region within the channel near the grounding line. As 


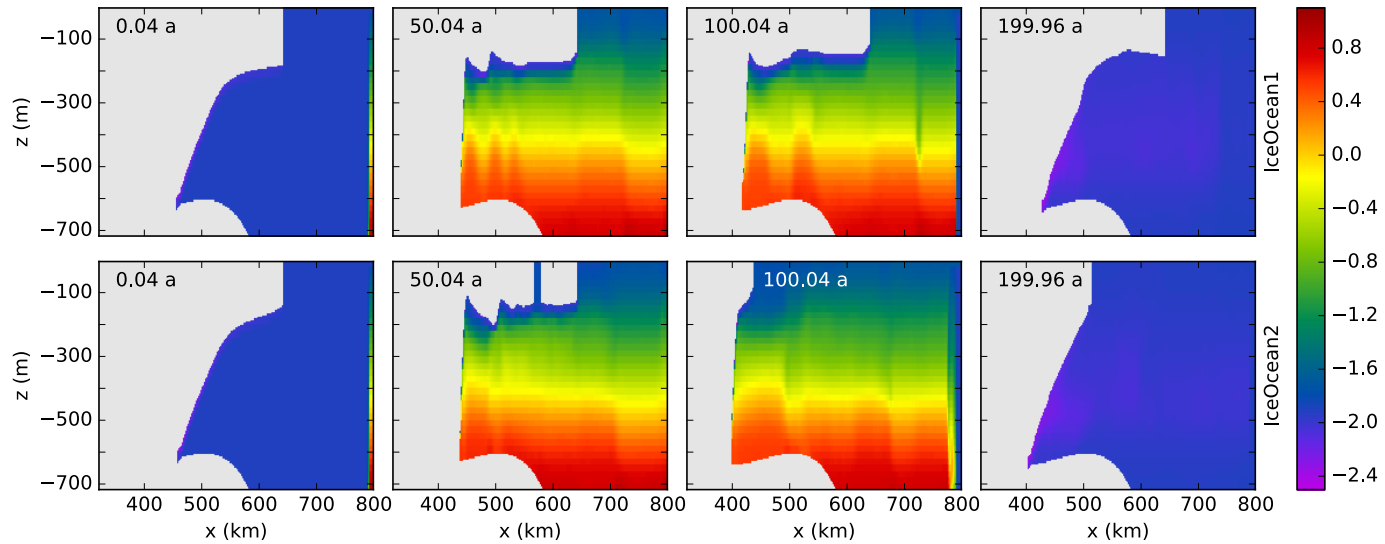

Figure 13. Example results from POPSICLES plotted as in Fig. 8 but for IceOcean1 (top) and IceOcean2 (bottom) simulations each lasting 200 years. Both simulations begin with ice shelves that are in steady state without melting and with COLD ocean conditions. The WARM far-field restoring in the ocean causes the melt rate to increase by several orders of magnitude over the first decade and for the ice shelf to thin over the remainder of the retreat phase (100 years). In IceOcean2, dynamic calving significantly reduces the size of the ice shelf compared with IceOcean1. During the final 100 years, the switch to COLD far-field restoring leads to cold ocean temperatures, melt rates are reduced by several orders of magnitude, and the ice shelf begins to re-advance; 100 years is not long enough for the ice shelf in either simulation to re-advance to its initial steady state.

the grounding line retreats, the area of the cavity increases (no calving occurs except beyond $x=640 \mathrm{~km}$ ) while the total melt flux remains nearly constant, meaning that the mean melt rate gradually decreases. Between year 100 and about year 130 , the melt rate decays by several orders of magnitude, reaching a nearly steady value for the remainder of the simulation as the ice shelf thickens and the grounding line begins to re-advance.

\subsection{IceOcean2 (optional): retreat and re-advance with dynamic calving}

Specifying calving was a major challenge in the design of MISOMIP1. There was general agreement in the community that ice-sheet models have not been shown to behave reliably with dynamic calving, while there is a lack of consensus about which calving parameterizations are appropriate or physically realistic. In Antarctica, calving events tend to be infrequent, producing large tabular icebergs, a process that is not well modeled by a continuous calving velocity or a simple calving criterion based on ice thickness (e.g., Sect. 3.1.2). Nevertheless, we felt that it was important for testing the robustness of the ice-sheet and ocean components in MISOMIP1 that there be an experiment with a dynamic, sheer cliff at the calving front. We include an optional coupled experiment, IceOcean2, that is identical to IceOcean1 except that it includes dynamic calving in the ice-sheet component. This experiment is designed test the ability of the icesheet component to apply dynamic calving, including detecting disconnected icebergs and the ability of the ocean component to handle abrupt changes in ice topography.

Whereas the MISMIP+ experiments do not include a dynamic calving front, IceOcean 2 prescribes the same simple calving criterion used in ISOMIP+: ice thinner than $H_{\text {calve }}=$ $100 \mathrm{~m}$ (equivalent to an ice draft above $\sim-90 \mathrm{~m}$ ) should be calved and the ice thickness set to zero. This thickness threshold was chosen for consistency with ISOMIP+, and allows the ice shelf to become thinner than would typically be observed in Antarctica. We also maintain the fixed-front calving condition from MISMIP + that ice beyond $x_{\text {calve }}=$ $640 \mathrm{~km}$ is removed. The calving criteria should be enforced in the ice-sheet component.

Because the calving criterion will change the steady state of the ice sheet, IceOcean 2 should begin with a new steadystate ice-sheet initial condition, again without melting but with the calving criterion imposed. For models that are performing a spinup to steady state, we recommend starting with the IceOcean 1 initial condition. This may also be an appropriate starting guess for those using continuation methods to find the initial steady state. As in MISMIP+, participants should modify the ice softness $(A)$ and, if necessary, the basal-traction coefficient $\left(\beta^{2}\right)$ so that the steadystate grounding line crosses the center of the trough at $x=$ $450 \pm 10 \mathrm{~km}$. Participants are asked to perform both the Ice 0 and Ice 1 experiments with the calving criterion. These results should be submitted along with the IceOcean 2 results. This will allow for a more complete analysis of the effects of calving on both the coupled and uncoupled systems.

Mean melt rates and grounded area from an example POPSICLES IceOcean 2 simulation are shown in the green curves in Fig. 12, and the evolution of the ice draft and ocean temperature are shown in the bottom row of Fig. 13. The beginning of the retreat phase of IceOcean 2 proceeds similarly to IceOcean1, with small differences due to the smaller, thinner ice shelf in the steady state with the calving criterion. Start- 
ing at around year 30, dynamic calving removes significant portions of the ice shelf. Although the melt flux remains relatively steady, the mean melt rate increases as the ice-shelf area decreases. Just after year 60 , a large iceberg breaks off from the ice shelf, leading to an abrupt decrease in ice-shelf area and a corresponding increase in the mean melt rate. For the remainder of the retreat phase, the ice shelf exists only as a small remnant of its initial size close to the grounding line. The re-advance phase begins at year 100 when the farfield restoring is switched to the COLD profiles. As the ocean cools, the melt rate decreases by several orders of magnitude. The ice-shelf area remains much smaller than in IceOcean1ra while melt fluxes are similar, meaning that the mean melt rate is nearly an order of magnitude higher.

\subsection{Component resolutions and parameterizations}

As in the ISOMIP+ experiments, we ask participants to perform the MISOMIP1 experiment once in a "common" (COM) configuration similar to that of ISOMIP+. For this configuration, the ocean component should have the same resolution and parameters as in the ISOMIP+ COM run. We do not prescribe the resolution of the ice-sheet component because the wider use of unstructured, dynamic and adaptive grids as well as higher-order elements in ice-sheet models compared with ocean models make it impractical to provide specifications that are appropriate for all models. Also, grounding-line dynamics in ice-sheet models have been shown to converge with resolution (e.g., Durand et al., 2009; Cornford et al., 2013; Leguy et al., 2014), whereas the same has not been shown for melt rates produced by ocean models.

Whereas we prescribed a "typical" run for ISOMIP+ with resolution and parameters that the ocean model typically uses for Antarctic regional simulations, it is not obvious that this is appropriate for MISOMIP1 models. Coupled ice sheetocean models are not well enough established to have typical resolutions and parameters. Therefore, we invite participants to submit several sets of results with parameter choices at their discretion in addition to the COM run and ensure these are well documented in the pdf describing the model and results.

The coupling interval for the model is left to each participant to decide. We recommend that participants perform a relatively short test with strong melting (e.g., initializing and forcing the coupled model with WARM conditions) to demonstrate convergence of the results with decreasing coupling intervals. For example, in POPSICLES, we have found in several tests that the mean melt rate and volume above flotation converge with coupling interval only when the coupling interval is 6 months or shorter. In the example results, POPSICLES was coupled monthly. We ask participants who are able to do so to provide multiple sets of results using different coupling intervals.

\subsection{Requested output}

We request that participants supply separate NetCDF files for their ice-sheet and ocean MISOMIP1 results. This allows the results to be supplied on different grids and is expected to simplify comparing the final results. NetCDF files with example output on the standard grids for each component are available (see Sect. 6). Participants are asked to supply all fields in 32-bit floating-point precision, with the file-naming convention of [expt]_COM_[component]_[MODEL_CONFIG] .nc, where [expt] is the experiment name from Table 2, COM indicates a verification run and is omitted for nonCOM runs, [component] is either ice or ocean and [MODEL_CONFIG] is a unique identifier for the coupledmodel configuration (e.g., the name of the model, the institute, ice stress approximation).

The requested ocean fields and the output grid are the same as in Sect. 3.3. The requested output from the ice-sheet component is the same as in MISMIP+ (see Sect. 2.3) with the exception that time is sampled monthly, the 2-D fields are required, rather than optional, and any units involving time should be given in s rather than a for consistency with the ocean output. As in MISMIP+, the 2-D ice-sheet fields should be interpolated from the ice-sheet model's native grid to the standard $1 \mathrm{~km}$ grid to simplify analysis.

The results should be accompanied by a pdf file giving details about the coupled model. In addition to the information requested in Sects. 2.3 and 3.3, this file should include a description of the coupling scheme and the length of the coupling interval.

\section{Conclusions}

Here, we have described the experimental design for three interrelated model intercomparison projects (MIPs): the third Marine Ice Sheet MIP (MISMIP+), the second Ice ShelfOcean MIP (ISOMIP+) and the first Marine Ice SheetOcean MIP (MISOMIP1). We expect that the results from each MIP will be published separately with all contributors as coauthors, following the tradition of the earlier MISMIPs.

We have demonstrated that all experiments are achievable with an example set of ice and ocean models (BISICLES, POP2 $x$ and POPSICLES), and that the results are consistent with the intended behavior behind the experimental design. The MISMIP+ experiments show significant grounding-line dynamics in response to forcing by basal melting (Ice1) and a large calving event (Ice2). One ISOMIP+ experiment, Ocean 0 , is designed to reach a quasi-steady state within 1 to 2 years, making it practical for parameter studies including calibrating the melt parameterization used in the remaining ISOMIP+ and MISOMIP1 experiments. Two ISOMIP+ experiments, Ocean 1 and Ocean2, demonstrate that changes in far-field forcing can lead to basal melting being signif- 
icantly enhanced or suppressed on decadal timescales. The remaining ISOMIP+ experiments, Ocean3 and Ocean4, provide a meaningful test of whether ocean models can handle dynamic ice-shelf topography. The main MISOMIP1 experiment, IceOcean1, demonstrates that changes in far-field ocean conditions can induce significant grounding-line dynamics. An optional experiment, IceOcean2, demonstrates that both the ice-sheet and ocean components can handle a dynamic calving front.

\section{Code and data availability}

The BISICLES ice-sheet model (Cornford et al., 2013) was used to produce the example MISMIP+ results and is the icesheet component of the POPSICLES model, which was used for the MISOMIP1 example results. The BISICLES source code is available via subversion at https://commons.lbl.gov/ display/bisicles/BISICLES. The example results were produced with svn revision $\mathrm{r} 2975$.

The source codes for the POP2x ocean model and the POPSICLES coupled model have not yet been made available to the public.

The Supplement for this article includes BISICLES Example results from all MISMIP+ experiments as well as a python script demonstrating how these data are written (specifically how to handle variations over time in the number of points describing the grounding line). Also included are pdf files describing the example results from all three MIPs to be used as templates for the participants. Finally, example python scripts are included for plotting the grounded area from MISMIP+ results as in Fig. 4 and various fields from ISOMIP+ and MISOMIP1 ocean results (similar to Fig. 8).

The ice topography data required for ISOMIP+ are too large to be included in the Supplement and have been archived separately in NetCDF4 format (Cornford and AsayDavis, 2016). These data come from a simulation of Ice1r and Ice1ra using BISICLES (svn revision r2825) with SSA and the basal friction parameterization from Weertman (1974).

The MISOMIP website (http://www.climate-cryosphere. org/activities/targeted/misomip) includes links to both NetCDF files and movie files showing the evolution of the example BISICLES, POP2x and POPSICLES simulations. We firmly wish to avoid giving the sense that the example results should be treated as a benchmark for the MIPs, and for this reason we do not feel it is appropriate to submit the results on their own to a data repository. Revised versions of the example results will be included along with submissions from other participants in a data repository as part of the analysis of each MIP.

The Supplement related to this article is available online at doi:10.5194/gmd-9-2471-2016-supplement.
Acknowledgements. This material is based upon work supported by the US Department of Energy, Office of Science, Office of Biological and Environmental Research under award nos. DESC0011982 and DE-SC0013038. Support was provided through NYU Abu Dhabi grant G1204. Simulation results were produced using resources of the National Energy Research Scientific Computing Center, a DOE Office of Science User Facility supported by the Office of Science of the US Department of Energy under contract no. DE-AC02-05CH11231. This work has received funding from the European Union Seventh Framework Programme (FP7/2007-2013) under grant agreement number 299035. Work at the Lawrence Berkeley National Laboratory was supported by the Director, Office of Science, Office of Advanced Scientific Computing Research, of the US Department of Energy under contract no. DE-AC02-05CH11231.

Edited by: P. Huybrechts

Reviewed by: D. Goldberg and two anonymous referees

\section{References}

Calov, R., Greve, R., Abe-Ouchi, A., Bueler, E., Huybrechts, P., Johnson, J. V., Pattyn, F., Pollard, D., Ritz, C., Saito, F., and Tarasov, L.: Results from the Ice-Sheet Model Intercomparison Project-Heinrich Event INtercOmparison (ISMIP HEINO), J. Glaciol., 56, 371-383, doi:10.3189/002214310792447789, 2010.

Cornford, S. L. and Asay-Davis, X. S.: Ice-shelf surface, basal and bedrock topography data for the second Ice Shelf-Ocean Model Intercomparison Project (ISOMIP+), GFZ Data Services, doi:10.5880/PIK.2016.002, 2016.

Cornford, S. L., Martin, D. F., Graves, D. T., Ranken, D. F., Le Brocq, A. M., Gladstone, R. M., Payne, A. J., Ng, E. G., and Lipscomb, W. H.: Adaptive mesh, finite volume modeling of marine ice sheets, J. Comput. Phys., 232, 529-549, doi:10.1016/j.jcp.2012.08.037, 2013.

De Rydt, J. and Gudmundsson, G. H.: Coupled ice shelf-ocean modeling and complex grounding line retreat from a seabed ridge, J. Geophys. Res., 121, 865-880, doi:10.1002/2015JF003791, 2016.

De Rydt, J., Holland, P. R., Dutrieux, P., and Jenkins, A.: Geometric and oceanographic controls on melting beneath Pine Island Glacier, J. Geophys. Res.-Oceans, 119, 2420-2438, doi:10.1002/2013JC009513, 2014.

Determann, J., Thoma, M., Grosfeld, K., and Massmann, S.: Impact of ice-shelf basal melting on inland ice-sheet thickness: a model study, Ann. Glaciol., 53, 129-135, doi:10.3189/2012AoG60A170, 2012.

Drouet, A. S., Docquier, D., Durand, G., Hindmarsh, R., Pattyn, F., Gagliardini, O., and Zwinger, T.: Grounding line transient response in marine ice sheet models, The Cryosphere, 7, 395-406, doi:10.5194/tc-7-395-2013, 2013.

Durand, G., Gagliardini, O., de Fleurian, B., Zwinger, T., and Le Meur, E.: Marine ice sheet dynamics: Hysteresis and neutral equilibrium, J. Geophys. Res., 114, F03009, doi:10.1029/2008JF001170, 2009.

Dutrieux, P., De Rydt, J., Jenkins, A., Holland, P. R., Ha, H. K., Lee, S. H., Steig, E. J., Ding, Q., Abrahamsen, E. P., and Schroder, M.: 
Strong Sensitivity of Pine Island Ice-Shelf Melting to Climatic Variability, Science, 3, 468-472, doi:10.1126/science.1244341, 2014.

Favier, L., Durand, G., Cornford, S. L., Gudmundsson, G. H., Gagliardini, O., Gillet-Chaulet, F., Zwinger, T., Payne, A. J., and Le Brocq, A. M.: Retreat of Pine Island Glacier controlled by marine ice-sheet instability, Nature Clim. Change, 5, 1-5, doi:10.1038/nclimate2094, 2014.

Feldmann, J. and Levermann, A.: Interaction of marine ice-sheet instabilities in two drainage basins: simple scaling of geometry and transition time, The Cryosphere, 9, 631-645, doi:10.5194/tc9-631-2015, 2015.

Feldmann, J., Albrecht, T., Khroulev, C., Pattyn, F., and Levermann, A.: Resolution-dependent performance of grounding line motion in a shallow model compared with a full-Stokes model according to the MISMIP3d intercomparison, J. Glaciol., 60, 353-360, doi:10.3189/2014JoG13J093, 2014.

Gagliardini, O., Cohen, D., Råback, P., and Zwinger, T.: Finiteelement modeling of subglacial cavities and related friction law, J. Geophys. Res., 112, F02027, doi:10.1029/2006JF000576, 2007.

Galton-Fenzi, B. K.: Modeling Ice-shelf/Ocean Interactions, PhD thesis, University of Tasmania, Hobart, Tasmania, Australia, 2009.

Gill, A. E.: Atmosphere-Ocean Dynamics (International Geophysics Series, Vol. 30), Academic Press, San Diego, CA, 1982.

Gladish, C. V., Holland, D. M., Holland, P. R., and Price, S. F.: Iceshelf basal channels in a coupled ice/ocean model, J. Glaciol., 58, 1527-1544, doi:10.3189/2012JoG12J003, 2012.

Gladstone, R. M., Payne, A. J., and Cornford, S. L.: Parameterising the grounding line in flow-line ice sheet models, The Cryosphere, 4, 605-619, doi:10.5194/tc-4-605-2010, 2010.

Goldberg, D. N., Little, C. M., Sergienko, O. V., Gnanadesikan, A., Hallberg, R., and Oppenheimer, M.: Investigation of land ice-ocean interaction with a fully coupled ice-ocean model: 1 . Model description and behavior, J. Geophys. Res., 117, F02037, doi:10.1029/2011JF002246, 2012a.

Goldberg, D. N., Little, C. M., Sergienko, O. V., Gnanadesikan, A., Hallberg, R., and Oppenheimer, M.: Investigation of land ice-ocean interaction with a fully coupled ice-ocean model: 2 . Sensitivity to external forcings, J. Geophys. Res., 117, F02038, doi:10.1029/2011JF002247, 2012b.

Grosfeld, K. and Sandhäger, H.: The evolution of a coupled ice shelf-ocean system under different climate states, Global Planet. Change, 42, 107-132, doi:10.1016/j.gloplacha.2003.11.004, 2004.

Grosfeld, K., Gerdes, R., and Determann, J.: Thermohaline circulation and interaction between ice shelf cavities and the adjacent open ocean, J. Geophys. Res., 102, 15595-15610, doi:10.1029/97JC00891, 1997.

Gudmundsson, G. H.: Ice-shelf buttressing and the stability of marine ice sheets, The Cryosphere, 7, 647-655, doi:10.5194/tc-7647-2013, 2013.

Gudmundsson, G. H., Krug, J., Durand, G., Favier, L., and Gagliardini, O.: The stability of grounding lines on retrograde slopes, The Cryosphere, 6, 1497-1505, doi:10.5194/tc-6-1497-2012, 2012.

Holland, D. M. and Jenkins, A.: Modeling Thermodynamic Ice-Ocean Interactions at the Base of an Ice Shelf,
J. Phys. Oceanogr., 29, 1787-1800, doi:10.1175/1520 0485(1999)029<1787:MTIOIA>2.0.CO;2, 1999.

Holland, D. M., Hunter, J., Grosfeld, K., Hellmer, H., Jenkins, A., Morales Maqueda, M. A., Hemer, M., Williams, M., Klinck, J. M., and Dinniman, M.: The Ice Shelf - Ocean Model Intercomparison Project (ISOMIP), Eos Trans. AGU, 84, Abstract C41A05, Fall Meet. Suppl., 2003.

Holland, P. R. and Feltham, D. L.: The Effects of Rotation and Ice Shelf Topography on Frazil-Laden Ice Shelf Water Plumes, J. Phys. Oceanogr., 36, 2312-2327, doi:10.1175/JPO2970.1, 2006.

Holland, P. R., Jenkins, A., and Holland, D. M.: The Response of Ice Shelf Basal Melting to Variations in Ocean Temperature, J. Climate, 21, 2558-2572, doi:10.1175/2007JCLI1909.1, 2008.

Hunter, J. R.: ISOMIP Files, available at: http://staff.acecrc.org.au/ 〜bkgalton/ISOMIP/ (last access: 21 July 2016), 2003.

Hunter, J. R.: Specification for test models of ice shelf cavities, Tech. Rep. June, Antarctic Climate \& Ecosystems Cooperative Research Centre, available at: http://staff.acecrc.org.au/ bkgalton/ISOMIP/test_cavities.pdf (last access: 21 July 2016), 2006.

Jenkins, A.: A One-Dimensional Model of Ice ShelfOcean Interaction, J. Geophys. Res., 96, 20671-20677, doi:10.1029/91JC01842, 1991.

Jenkins, A., Hellmer, H. H., and Holland, D. M.: The Role of Meltwater Advection in the Formulation of Conservative Boundary Conditions at an Ice-Ocean Interface, J. Phys. Oceanogr., 31, 285-296, doi:10.1175/15200485(2001)031<0285:TROMAI>2.0.CO;2, 2001.

Jenkins, A., Nicholls, K. W., and Corr, H. F. J.: Observation and Parameterization of Ablation at the Base of Ronne Ice Shelf, Antarctica, J. Phys. Oceanogr., 40, 2298-2312, doi:10.1175/2010JPO4317.1, 2010.

Joughin, I., Smith, B. E., and Medley, B.: Marine ice sheet collapse potentially under way for the Thwaites Glacier Basin, West Antarctica, Science, 344, 735-738, doi:10.1126/science.1249055, 2014.

Kimura, S., Candy, A., Holland, P., Piggott, M., and Jenkins, A.: Adaptation of an unstructured-mesh, finite-element ocean model to the simulation of ocean circulation beneath ice shelves, Ocean Model., 67, 39-51, doi:10.1016/j.ocemod.2013.03.004, 2013.

Leguy, G. R., Asay-Davis, X. S., and Lipscomb, W. H.: Parameterization of basal friction near grounding lines in a one-dimensional ice sheet model, The Cryosphere, 8, 1239-1259, doi:10.5194/tc8-1239-2014, 2014.

Losch, M.: Modeling ice shelf cavities in a $\mathrm{z}$ coordinate ocean general circulation model, J. Geophys. Res., 113, 1-15, doi:10.1029/2007JC004368, 2008.

MacAyeal, D., Rommelaere, V., Huybrechts, P., Hulbe, C., Determann, J., and Ritz, C.: An ice-shelf model test based on the Ross ice shelf, Ann. Glaciol., 23, 46-51, 1996.

McPhee, M. G., Morison, J. H., and Nilsen, F.: Revisiting heat and salt exchange at the ice-ocean interface: Ocean flux and modeling considerations, J. Geophys. Res., 113, 1-10, doi:10.1029/2007JC004383, 2008.

Oey, L.-Y.: An OGCM with movable land-sea boundaries, Ocean Model., 13, 176-195, doi:10.1016/j.ocemod.2006.01.001, 2006.

Pattyn, F., Perichon, L., Aschwanden, A., Breuer, B., de Smedt, B., Gagliardini, O., Gudmundsson, G. H., Hindmarsh, R. C. A., Hubbard, A., Johnson, J. V., Kleiner, T., Konovalov, Y., Martin, 
C., Payne, A. J., Pollard, D., Price, S., Rückamp, M., Saito, F., Souček, O., Sugiyama, S., and Zwinger, T.: Benchmark experiments for higher-order and full-Stokes ice sheet models (ISMIPHOM), The Cryosphere, 2, 95-108, doi:10.5194/tc-2-95-2008, 2008.

Pattyn, F., Schoof, C., Perichon, L., Hindmarsh, R. C. A., Bueler, E., de Fleurian, B., Durand, G., Gagliardini, O., Gladstone, R., Goldberg, D., Gudmundsson, G. H., Huybrechts, P., Lee, V., Nick, F. M., Payne, A. J., Pollard, D., Rybak, O., Saito, F., and Vieli, A.: Results of the Marine Ice Sheet Model Intercomparison Project, MISMIP, The Cryosphere, 6, 573-588, doi:10.5194/tc6-573-2012, 2012.

Pattyn, F., Perichon, L., Durand, G., Favier, L., Gagliardini, O., Hindmarsh, R. C. A., Zwinger, T., Albrecht, T., Cornford, S., Docquier, D., Fürst, J. J., Goldberg, D., Gudmundsson, G. H., Humbert, A., Hütten, M., Huybrechts, P., Jouvet, G., Kleiner, T., Larour, E., Martin, D., Morlighem, M., Payne, A. J., Pollard, D., Rückamp, M., Rybak, O., Seroussi, H., Thoma, M., and Wilkens, N.: Grounding-line migration in plan-view marine icesheet models: results of the ice2sea MISMIP3d intercomparison, J. Glaciol., 59, 410-422, doi:10.3189/2013JoG12J129, 2013.

Payne, A., Huybrechts, P., Abe-Ouchi, A., Calov, R., Fastook, J. L., Greve, R., Marshall, S. J., Marsiat, I., Ritz, C., Tarasov, L., and Thomassen, M. P. A.: Results from the EISMINT model intercomparison: the effects of thermomechanical coupling, J. Glaciol., 46, 227-238, doi:10.3189/172756500781832891, 2000.

Pond, S. and Pickard, G. L.: Introductory Dynamical Oceanography, Second Edition, Butterworth-Heinemann, Oxford, UK, 1983.

Schoof, C.: The effect of cavitation on glacier sliding, P. Roy. Soc. A-Math. Phy., 461, 609-627, doi:10.1098/rspa.2004.1350, 2005.

Schoof, C.: Marine ice-sheet dynamics. Part 1. The case of rapid sliding, J. Fluid Mech., 573, 27, doi:10.1017/S0022112006003570, 2007a.

Schoof, C.: Ice sheet grounding line dynamics: Steady states, stability, and hysteresis, J. Geophys. Res., 112, 1-19, doi:10.1029/2006JF000664, 2007b.

Schoof, C. and Hindmarsh, R. C. A.: Thin-Film Flows with Wall Slip: An Asymptotic Analysis of Higher Order Glacier Flow Models, Q. J. Mech. Appl. Math., 63, 73-114, doi:10.1093/qjmam/hbp025, 2010.
Sergienko, O. V.: Basal channels on ice shelves, J. Geophys. Res.Earth, 118, 1342-1355, doi:10.1002/jgrf.20105, 2013.

Sergienko, O. V., Goldberg, D. N., and Little, C. M.: Alternative ice shelf equilibria determined by ocean environment, J. Geophys. Res.-Earth, 118, 970-981, doi:10.1002/jgrf.20054, 2013.

Seroussi, H., Morlighem, M., Larour, E., Rignot, E., and Khazendar, A.: Hydrostatic grounding line parameterization in ice sheet models, The Cryosphere, 8, 2075-2087, doi:10.5194/tc-8-20752014, 2014a.

Seroussi, H., Morlighem, M., Rignot, E., Mouginot, J., Larour, E., Schodlok, M., and Khazendar, A.: Sensitivity of the dynamics of Pine Island Glacier, West Antarctica, to climate forcing for the next 50 years, The Cryosphere, 8, 1699-1710, doi:10.5194/tc-81699-2014, 2014b.

Thoma, M., Grosfeld, K., Mayer, C., and Pattyn, F.: Interaction between ice sheet dynamics and subglacial lake circulation: a coupled modelling approach, The Cryosphere, 4, 1-12, doi:10.5194/tc-4-1-2010, 2010.

Tsai, V. C., Stewart, A. L., and Thompson, A. F.: Marine ice-sheet profiles and stability under Coulomb basal conditions, J. Glaciol., 61, 205-215, doi:10.3189/2015JoG14J221, 2015.

Walker, R. T. and Holland, D. M.: A two-dimensional coupled model for ice shelf-ocean interaction, Ocean Model., 17, 123 139, doi:10.1016/j.ocemod.2007.01.001, 2007.

Walker, R. T., Dupont, T. K., Parizek, B. R., and Alley, R. B.: Effects of basal-melting distribution on the retreat of ice-shelf grounding lines, Geophys. Res. Lett., 35, L17503, doi:10.1029/2008GL034947, 2008.

Walker, R. T., Dupont, T. K., Holland, D. M., Parizek, B. R., and Alley, R. B.: Initial effects of oceanic warming on a coupled ocean-ice shelf-ice stream system, Earth Planet. Sc. Lett., 287, 483-487, doi:10.1016/j.epsl.2009.08.032, 2009.

Walker, R. T., Holland, D. M., Parizek, B. R., Alley, R. B., Nowicki, S. M. J., and Jenkins, A.: Efficient flowline simulations of iceshelf/ocean interactions: Sensitivity studies with a fully coupled model, J. Phys. Oceanogr., 43, 2200-2210, doi:10.1175/JPO-D13-037.1, 2013.

Weertman, J.: Stability of the junction of an ice sheet and an ice shelf, J. Glaciol., 13, 3-11, 1974. 